University of Tennessee Health Science Center

UTHSC Digital Commons

\title{
Compound 49b: A Novel Beta-Adrenergic Receptor Agonist in the Treatment of Diabetic Retinopathy
}

Kimberly Williams-Guy

University of Tennessee Health Science Center

Follow this and additional works at: https://dc.uthsc.edu/dissertations

Part of the Chemicals and Drugs Commons, Endocrine System Diseases Commons, Medicinal and Pharmaceutical Chemistry Commons, and the Pharmaceutics and Drug Design Commons

\section{Recommended Citation}

Williams-Guy, Kimberly , "Compound 49b: A Novel Beta-Adrenergic Receptor Agonist in the Treatment of Diabetic Retinopathy" (2011). Theses and Dissertations (ETD). Paper 290. http://dx.doi.org/10.21007/ etd.cghs.2011.0349.

This Thesis is brought to you for free and open access by the College of Graduate Health Sciences at UTHSC Digital Commons. It has been accepted for inclusion in Theses and Dissertations (ETD) by an authorized administrator of UTHSC Digital Commons. For more information, please contact jwelch30@uthsc.edu. 


\title{
Compound 49b: A Novel Beta-Adrenergic Receptor Agonist in the Treatment of Diabetic Retinopathy
}

\begin{abstract}
Diabetic retinopathy is the leading cause of blindness in working Americans. While there are therapeutic regimens for the disease, more effective methods are needed. We have previously shown that a nonspecific beta-adrenergic receptor agonist, isoproterenol, was effective in preventing functional and morphological changes associated with diabetic retinopathy in the rat. Isoproterenol also produced left ventricle remodeling suggesting it entered the systemic circulation. We therefore synthesized various novel beta-adrenergic receptor compounds and screened these compounds in vitro for their ability to reduce markers of inflammation and apoptosis. Of the various compounds tested, Compound 49b was able to reduce both inflammation and apoptosis in vitro in both retinal endothelial cells (REC) and Müller cells and did so at a significantly lower concentration than isoproterenol, deeming it the most effective compound.
\end{abstract}

Objective. We evaluated the effectiveness of Compound $49 \mathrm{~b}$ to prevent and delay changes associated with diabetic retinopathy without systemic effects. We hypothesized that topical application of Compound $49 \mathrm{~b}$ could prevent and delay the onset of functional and morphological markers of diabetic retinopathy and restore retinal cellular signaling, without affecting the heart.

Methods. Male rats were made diabetic with a streptozotocin injection $(60 \mathrm{mg} / \mathrm{kg})$. Two days after the injection, glucose measurements were obtained. Two groups of rats were used for these two separate studies. In the prevention studies, a subset of the diabetic rats were started on daily $1 \mathrm{mM}$ Compound $49 \mathrm{~b}$ eye drops for either 2-months or 8-months upon the verification of diabetes, while the control and diabetic only subgroups received no treatment. In the delayed treated studies, animals were placed on Compound $49 \mathrm{~b}$ after 6-months of untreated diabetes. Once optimal dose and time course was obtained, body weight, blood glucose, intraocular pressure, blood pressure, and electrical activity of the retina were measured monthly over the duration of the prevention and delayed treatment studies. Insulin signaling, tumor necrosis factor!alpha (TNF-!) levels, and cleavage of caspase 3 were analyzed after 2- and 8-months or 2and 6-months of treatment.

Results. Protein levels of TNF-! and cleaved caspase 3 were increased in the retinas of diabetic rats, but were returned to normal values following $1 \mathrm{mM}$ Compound $49 \mathrm{~b}$ treatment. Since we have previously found that topical isoproterenol produced left ventricular remodeling, we wanted to investigate whether Compound $49 \mathrm{~b}$ could overcome this obstacle. Left ventricular samples from diabetes+Compound 49btreated rats were not significantly different than diabetes alone rats after statistical analyses.

Conclusion. Data showed that daily topical $1 \mathrm{mM}$ Compound $49 \mathrm{~b}$ eye drops reduced TNF-! levels and cleaved caspase 3 levels, while maintaining insulin receptor signal transduction in the diabetic retina. Additionally, Compound 49b maintained retinal electrical activity, as measured by electroretinogram (ERG) analysis. Data indicates that Compound $49 \mathrm{~b}$ does not reach the systemic circulation or alter blood pressure or intraocular pressure, suggesting that it may represent a novel treatment option for diabetic retinopathy.

\section{Document Type}

Thesis

\section{Degree Name}

Master of Science (MS) 


\section{Program}

Biomedical Sciences

Research Advisor

Jena J. Steinle, Ph.D.

\section{Keywords}

apoptosis, diabetes, inflammation, retina

\section{Subject Categories}

Chemicals and Drugs | Diseases | Endocrine System Diseases | Medicinal and Pharmaceutical Chemistry | Medicine and Health Sciences | Pharmaceutics and Drug Design | Pharmacy and Pharmaceutical

Sciences 


\title{
Compound 49b: A Novel Beta-Adrenergic Receptor Agonist in the Treatment of Diabetic Retinopathy
}

\author{
A Thesis \\ Presented for \\ The Graduate Studies Council \\ The University of Tennessee \\ Health Science Center
}

\begin{abstract}
In Partial Fulfillment
Of the Requirements for the Degree

Master of Science

From The University of Tennessee
\end{abstract}

By

Kimberly Williams-Guy

December 2011 
Copyright (C) 2011 by Kimberly Williams-Guy. All rights reserved. 


\section{DEDICATION}

This thesis is dedicated to my husband

Andre Ventez Guy

and my parents

Mr. Eddie Lee Williams and Mrs. Karen Patricia Williams

for their support, encouragement, and love. 


\section{ACKNOWLEDGEMENTS}

I would like to thank my committee for their help, advice, and support throughout the duration of my graduate career. Dr. Edward Chaum, Dr. Monica Jablonski, Dr. Duane Miller, and Dr. Charles Yates contributed very helpful and beneficial comments, and my committee advisor Dr. Jena J. Steinle successfully and wonderfully guided my overall project. I sincerely and deeply acknowledge the love, support, and strength from my husband, Andre V. Guy. I love you and thank you from the bottom of my heart. Without you by my side, none of this would be possible. I would like to thank my son, Malique Andre Guy, for coming into my life and giving me the drive to achieve. Mommy loves you! I would finally like to thank my family and friends who supported me, and especially my true friend and lab peer, Robert Jason Walker, for always being there when I needed you. 


\begin{abstract}
Diabetic retinopathy is the leading cause of blindness in working Americans. While there are therapeutic regimens for the disease, more effective methods are needed. We have previously shown that a non-specific beta-adrenergic receptor agonist, isoproterenol, was effective in preventing functional and morphological changes associated with diabetic retinopathy in the rat. Isoproterenol also produced left ventricle remodeling suggesting it entered the systemic circulation. We therefore synthesized various novel beta-adrenergic receptor compounds and screened these compounds in vitro for their ability to reduce markers of inflammation and apoptosis. Of the various compounds tested, Compound $49 \mathrm{~b}$ was able to reduce both inflammation and apoptosis in vitro in both retinal endothelial cells (REC) and Müller cells and did so at a significantly lower concentration than isoproterenol, deeming it the most effective compound.
\end{abstract}

Objective. We evaluated the effectiveness of Compound $49 \mathrm{~b}$ to prevent and delay changes associated with diabetic retinopathy without systemic effects. We hypothesized that topical application of Compound $49 \mathrm{~b}$ could prevent and delay the onset of functional and morphological markers of diabetic retinopathy and restore retinal cellular signaling, without affecting the heart.

Methods. Male rats were made diabetic with a streptozotocin injection $(60 \mathrm{mg} / \mathrm{kg})$. Two days after the injection, glucose measurements were obtained. Two groups of rats were used for these two separate studies. In the prevention studies, a subset of the diabetic rats were started on daily $1 \mathrm{mM}$ Compound $49 \mathrm{~b}$ eye drops for either 2 -months or 8 -months upon the verification of diabetes, while the control and diabetic only subgroups received no treatment. In the delayed treated studies, animals were placed on Compound 49b after 6-months of untreated diabetes. Once optimal dose and time course was obtained, body weight, blood glucose, intraocular pressure, blood pressure, and electrical activity of the retina were measured monthly over the duration of the prevention and delayed treatment studies. Insulin signaling, tumor necrosis factor-alpha (TNF- $\alpha$ ) levels, and cleavage of caspase 3 were analyzed after 2- and 8 -months or 2- and 6-months of treatment.

Results. Protein levels of TNF- $\alpha$ and cleaved caspase 3 were increased in the retinas of diabetic rats, but were returned to normal values following $1 \mathrm{mM}$ Compound $49 \mathrm{~b}$ treatment. Since we have previously found that topical isoproterenol produced left ventricular remodeling, we wanted to investigate whether Compound $49 \mathrm{~b}$ could overcome this obstacle. Left ventricular samples from diabetes + Compound $49 \mathrm{~b}$-treated rats were not significantly different than diabetes alone rats after statistical analyses.

Conclusion. Data showed that daily topical $1 \mathrm{mM}$ Compound $49 \mathrm{~b}$ eye drops reduced TNF- $\alpha$ levels and cleaved caspase 3 levels, while maintaining insulin receptor signal transduction in the diabetic retina. Additionally, Compound 49b maintained retinal electrical activity, as measured by electroretinogram (ERG) analysis. Data indicates that Compound $49 \mathrm{~b}$ does not reach the systemic circulation or alter blood 
pressure or intraocular pressure, suggesting that it may represent a novel treatment option for diabetic retinopathy. 


\section{TABLE OF CONTENTS}

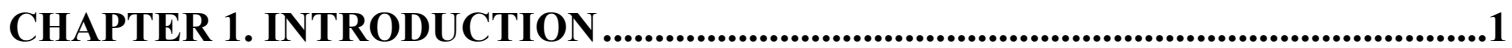

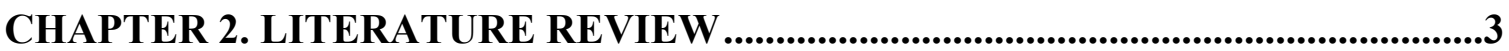

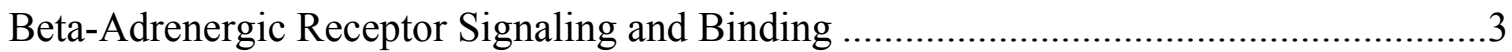

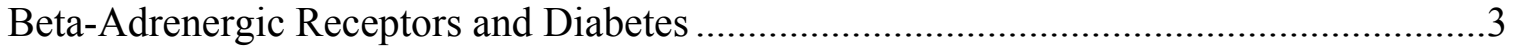

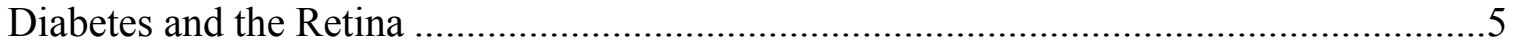

Diabetes in Heart, Lungs, and Kidneys ....................................................................5

Autonomic Nervous System Signaling: Adrenergic Receptors.........................................5

Beta-Adrenergic Receptors: The Retina ……………...................................................6

Hypotheses of Diabetic Retinopathy .......................................................................6

CHAPTER 3. COMPOUND 12: BETA-ADRENERGIC RECEPTOR SIGNALING BY THE ISOMERS OF ISOPROTERENOL AND LIKE DRUGS IN RETINAL ENDOTHELIAL CELLS AND MÜLLER CELLS...............................10

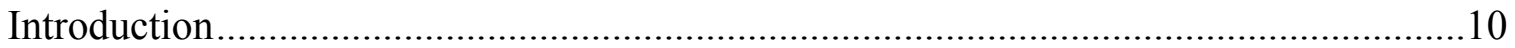

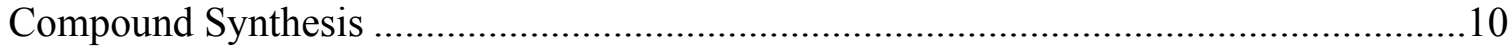

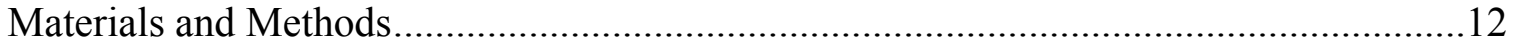

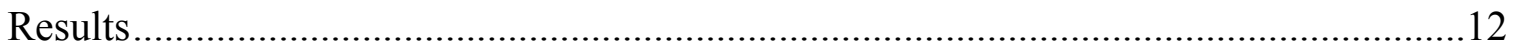

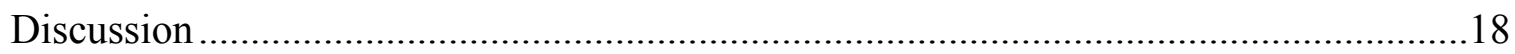

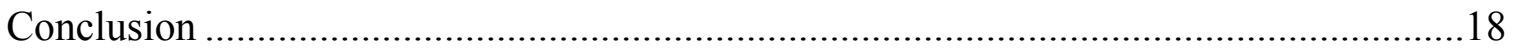

CHAPTER 4. COMPOUND 49B: A NOVEL BETA-ADRENERGIC

RECEPTOR AGONIST IN THE TREATMENT OF DIABETIC

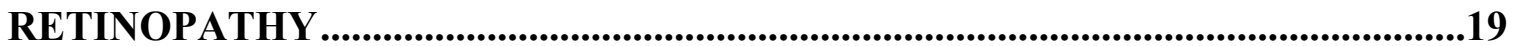

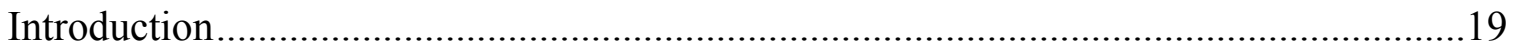

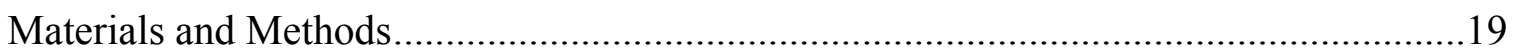

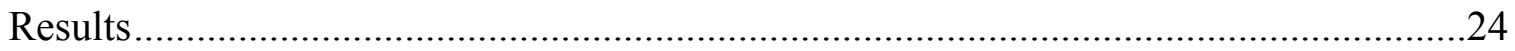

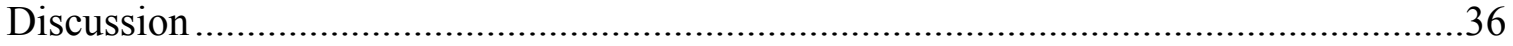

CHAPTER 5. SUMMARY AND CONCUSIONS ..................................................43

Correlations: Clinical and Non-Clinical Findings of Diabetic Retinopathy .......................43

The Novel Compound 49b.......................................................................................43

Effects of Diabetes on Beta-Adrenergic Receptor Signaling ............................................43

Advantages of Compound 49b over Isoproterenol .........................................................4

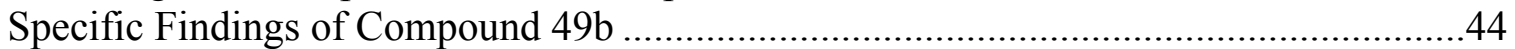

Potential Mechanisms of Action for Compound 49b ……….........................................45

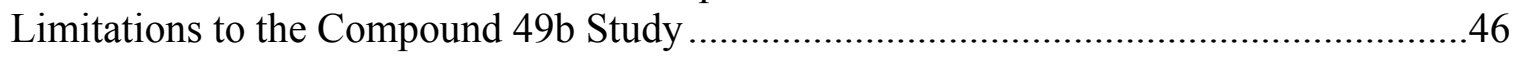

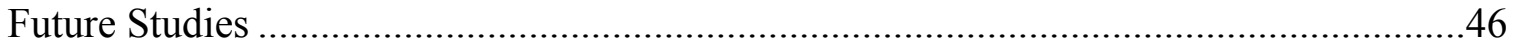

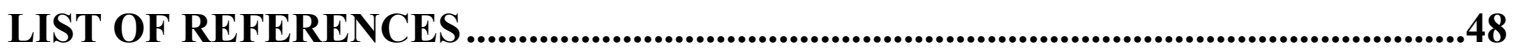

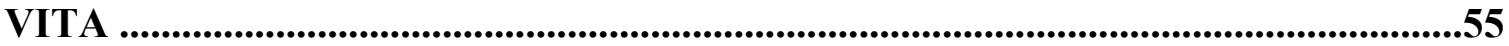




\section{LIST OF TABLES}

Table 4-1. Prevention Study Vital Measurements. ...................................................25

Table 4-2. $\quad$ Delayed Treatment Study Vital Measurements...........................................26 


\section{LIST OF FIGURES}

Figure 2-1. Adrenergic Receptor Signaling...............................................................

Figure 2-2. Hypothesis of Diabetic Retinopathy............................................................

Figure 3-1. Chemical Structures of Isoproterenol. ..........................................................11

Figure 3-2. Chemical Structure of Xamoterol...............................................................13

Figure 3-3. Cleaved Caspase 3 Results in REC for Compounds R-1, 10, 11, and 12....14

Figure 3-4. TNF- $\alpha$ Activity Results in REC for Compounds 10 and 12 .......................15

Figure 3-5. Cleaved Caspase 3 Results in Müller Cells for Compounds R-1, S-1, 11,

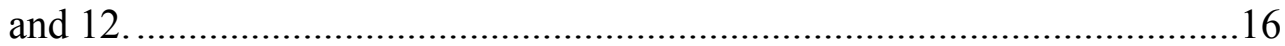

Figure 3-6. TNF- $\alpha$ Activity Results in Müller Cells for Compounds R-1, S-1, 10, 11

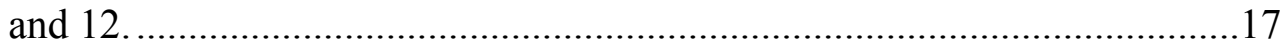

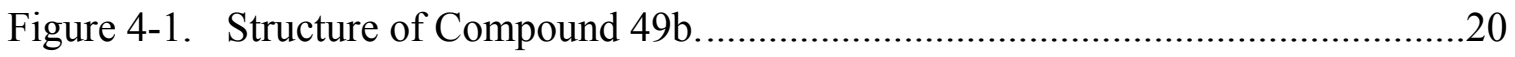

Figure 4-2. Bar Graph of Cleaved Caspase 3 and TNF- $\alpha$ Protein Levels on Retinal Endothelial Cells.....................................................................................2

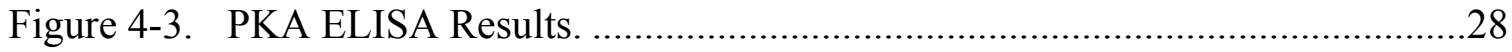

Figure 4-4. ERG Waveforms and Graphs after Compound 49b Treatment from the Prevention Group ……………………………………………………........

Figure 4-5. ERG Waveforms and Graphs after Compound 49b Treatment from the Delayed Treatment Group.............................................................................

Figure 4-6. Results of Retinal Thickness and Ganglion Cell Layer Count. ......................32

Figure 4-7. Bar Graph of Acellular Capillaries per Millimeter Squared of Retinal Tissue and Pericyte Ghost Counts of Control (Ctrl), Diabetic, and Treatment Rats $(\mathrm{Diab}+49 \mathrm{~b})$.

Figure 4-8. Results from Cleaved Caspase 3 ELISA on Retinal Lysates from Control (Ctrl), Diabetic, and Diabetic+Treatment Rats (Diab+49b).

Figure 4-9. Bar Graph of the Ratio of Phosphorylated Akt and Total Akt Protein Levels.

Figure 4-10. Bar Graph of the Ratio of Phosphorylated Insulin Receptor Beta (IRB) to Total Insulin Receptor Beta Protein Levels. 
Figure 4-11. Results from TNF- $\alpha$ ELISA on Retinal Lysates from Control (Ctrl), Diabetic, and Diabetic+Treatment Rats (Diab+49b) . ...............................38

Figure 4-12. Bar Graph of the Ratio of Phosphorylated and Total Insulin Receptor Substrate-1 Protein Levels. ........................................................................39

Figure 4-13. Heart Images from Control, Diabetic, and Diabetic+Compound 49b Rats. . .40 


\section{CHAPTER 1. INTRODUCTION}

Diabetic retinopathy has been shown to be the leading cause of blindness in working Americans (Frank 2004). Complications of the disease include inflammatory cytokine up-regulation (Kowluru \& Odenbach 2004), TNF- $\alpha$ mediated apoptosis (Joussen et al 2009), neuronal and vascular changes, pericyte loss, basement membrane thickening, and neovascularization (Wiley et al 2005). Present therapy for diabetic retinopathy includes vitrectomy and laser photocoagulation therapy. These therapies are highly effective clinically, however side effects from both procedures have risks, such as some permanent vision loss and retinal detachment (Chew et al 2003). Therefore, we began to hypothesize and investigate a potential mechanism by which reduction of retinal changes induced by diabetes could be accomplished.

Early in vivo work in our lab showed that after surgical sympathectomy retinal and choroidal changes were seen in the eye (Steinle 2003) and these changes were similar to diabetes-induced changes in the eye, including basement membrane thickness and pericyte ghost formation. In addition, previous work in our lab also showed that in vitro stimulation with propranolol, a beta-adrenergic receptor antagonist, caused similar changes as those seen after surgical sympathectomy while the alpha-adrenergic receptor antagonist, phentolamine, produced no changes (Steinle 2002). Because treatment with propranolol caused changes that were similar to sympathectomy, and stimulation with the alpha-adrenergic receptor antagonist showed no changes, we hypothesized that stimulation with a beta-adrenergic receptor agonist may prevent retinal changes induced by diabetes. Further work investigating beta-adrenergic receptor stimulation showed that apoptotic (Williams et al 2009) and inflammatory markers (Steinle et al 2007) were reduced significantly in vitro.

It was possible that surgical ganglionectomy could cause the biochemical, vascular, and neuronal changes as seen in diabetic retinopathy (Frank 2004) and to determine this, a genetic model was used. The dopamine beta-hydroxylase knock-out (DBH-KO) model was used because it was previously shown that decreased norepinephrine levels were consistent with detrimental retinal manifestations (Jandrastis et al 2002). We found that in the absence of dopamine beta-hydroxylase, similar biochemical, vascular, and neuronal changes occurred in the retina as seen post sympathectomy (Panjala et al 2010). After reviewing these findings, we hypothesized that restoration of beta-adrenergic receptor signaling may improve retinal changes associated with diabetic retinopathy; specifically that beta-receptor stimulation could possibly modulate changes in the retina induced by diabetes.

This thesis introduces a novel, beta-adrenergic receptor agonist, Compound 49b, whose treatment has shown to significantly reduce markers of diabetic retinopathy more effectively than similar beta-adrenergic receptor agonist compounds tested. In addition to in vitro and in vivo experimentation, we also hypothesized the potential signaling mechanism by which Compound $49 \mathrm{~b}$ exerts its actions, and carried out non-invasive functional testing to gain more insight on the influence compound administration had on 
the retina and internal homeostasis. Collectively, these findings may contribute to understanding the progression of diabetic retinopathy and the novel compound presented here may be a possible therapeutic intervention for treatment of the disease. 


\section{CHAPTER 2. LITERATURE REVIEW}

This Review of the Literature of diabetic retinopathy and its retinal complications consists of topics beginning with diabetes and how it effects organs and beta-adrenergic signaling, leading up to our hypotheses on signaling mechanism involved in the progression of diabetic retinopathy. This chapter includes a detailed discussion with literary findings, supporting our hypotheses and theory behind Compound 49b actions.

\section{Beta-Adrenergic Receptor Signaling and Binding}

Beta and alpha-adrenergic receptors belong to a very large family of hormone receptors (Joost et al 2002), which are linked with guanine nucleotide-binding regulatory proteins (G-proteins), $\mathrm{G}_{\mathrm{s}}$ and $\mathrm{G}_{\mathrm{i}}$ among others, and together are commonly known as G-protein coupled receptors (GPCR) (Chen-Izu et al 2000). $\mathrm{G}_{\mathrm{s}}$ is the stimulatory subunit of the receptor and $\mathrm{G}_{\mathrm{i}}$ is the inhibitory subunit of the receptor (Wettschureck \& Offermanns 2005). The majority of GPCRs share a common structural motif consisting of seven trans membrane helices (Ghanouni et al 2001). Once an agonist binds to the adrenergic receptor, the GPCR undergoes a conformational change and initiates intracellular signaling events (Bortolato et al 2009).

Adrenergic receptors can be divided in to two main groups, alpha and beta, with several subtypes (Chen-Izu et al 2000) (Figure 2-1). Alpha-receptor subtypes include $A_{1}$ and $A_{2}$ and beta--receptors subtypes include $B_{1}, B_{2}$, and $B_{3}$ (Sagrada et al 1987). It is generally assumed that once an agonist binds to the beta-receptor, the receptor-associated G-protein is activated (Vassilatis et al 2003) and stimulates adenylyl cyclase to make cyclic adenosine monophosphate (cAMP), which in turn activates protein kinase A (PKA) and activates other downstream signaling molecules. In contrast, alpha receptors activate phospholipase $\mathrm{C}$ ( $\mathrm{A}_{1}$ receptors) or inactivate adenylyl cyclase ( $\mathrm{A}_{2}$ receptors) (Schmitz et al 1981).

\section{Beta-Adrenergic Receptors and Diabetes}

Diabetes is the result of the body's inability to produce insulin, as in type I diabetes mellitus, or the body's inability to properly use insulin, as in type II diabetes mellitus (Wild et al 2004). Insulin is an important hormone and signaling molecule involved with diabetes (Steiner \& Oyer 1967) and its normal function is critical to maintenance of homeostasis and in treatment of the disease. While literature suggests that there may be crosstalk between the insulin receptor and the GPCR in pancreatic cancer cells (Walker 2007), crosstalk has not been characterized in the retina. These findings suggest that the beta-adrenergic receptor may be a target in regulation of the complications of diabetes in the retina. 


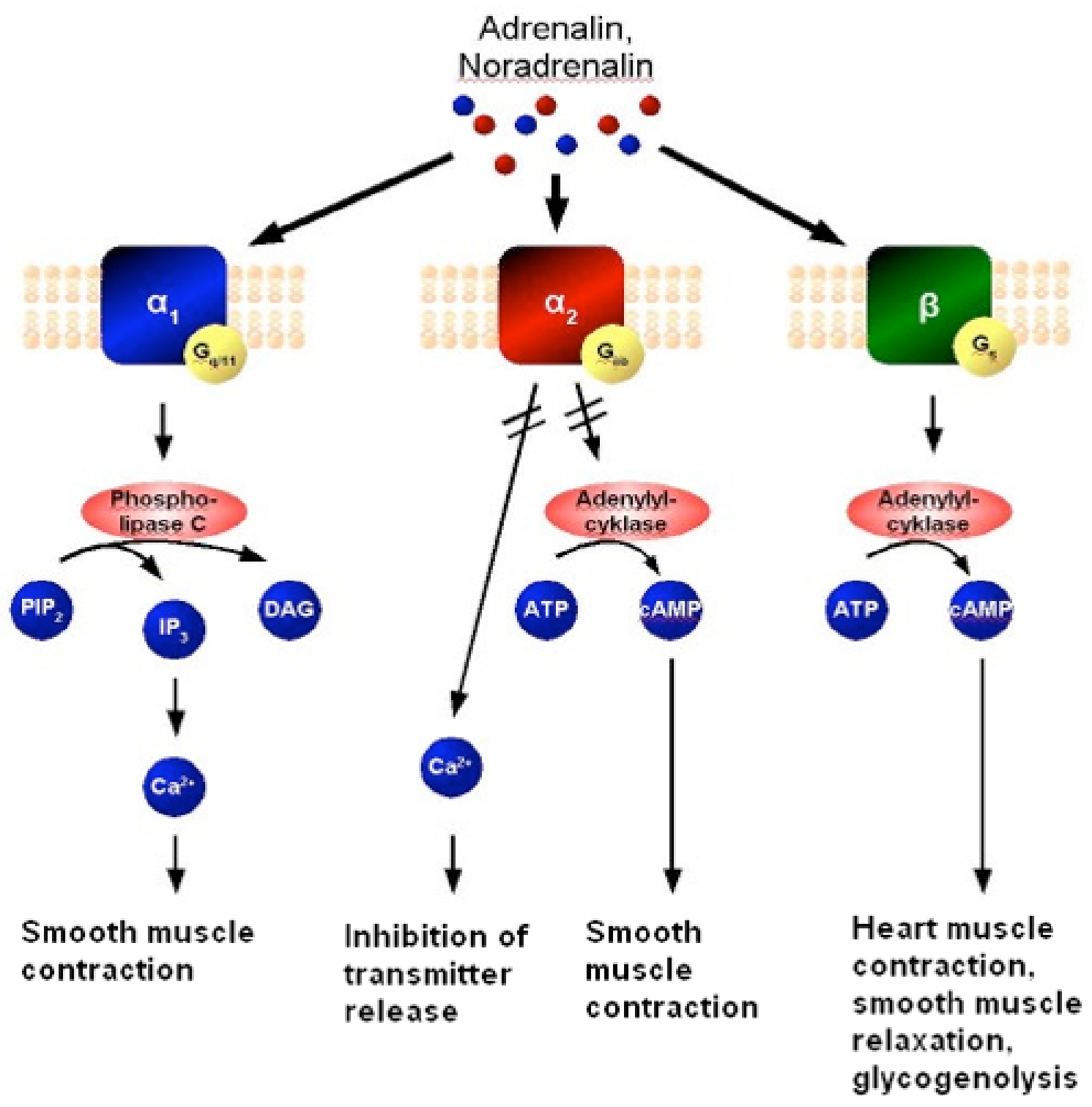

Figure 2-1. Adrenergic Receptor Signaling.

Giubergia, V., Zelazko, M., Roy, A., Gravina, L.P., Pena, H.G., \& Chertkoff, L. (2009). Beta-2 AR polymorphism (homozygous arginine 16) associated with higher IgE in children with asthma. Asth and Immunol., 102, (4), 308-313. Reprinted with permission. 


\section{Diabetes and the Retina}

The damage to the retina is characteristic of diabetic retinopathy, the leading cause of blindness in working adults (Frank 2004). Long-term complications of diabetes can induce changes to the retina such as increased retinal thickness due to accumulation of fluid in the macula (Aiello 1998). In diabetic retinopathy, elevated glucose induces pericyte cell death (Ejaz et al 2008), the cells which support endothelial cells in retinal blood vessels, and thickening of the basement membranes of these vessels (Pardianto 2005), producing incompetent and permeable blood vessels. Clinical manifestations of non-proliferative retinopathy include retinal bleeding (Davis et al 1998), venous beading, or intraretinal microvascular anomalies (IRMA) (Flynn \& Tooke 1992). The progression from the non-proliferative stage to the proliferative stage is due to a reduction in oxygen inducing proliferation of faulty blood vessels in the retina. The proliferative stage of diabetic is indicative of new blood vessels on the surface of the optic nerve head, known as neovascularization of the disc (NVD) or the retina itself, known as neovascularization elsewhere (NVE) (Davis et al 1998; Sharma \& Chandrarajan 2004). While laser and panretinal photocoagulation have shown been to slow progression of blindness in the disease (Fraser-Bell et al 2008), novel therapies are still needed, due to side effects presented earlier which are associated with current therapies.

\section{Diabetes in Heart, Lungs, and Kidneys}

Diabetes has been shown to induce cardiac dysfunction, more specifically, diabetic cardiomyopathy. Diabetic cardiomyopathy is characterized functionally by ventricular dysfunction (Avogaro 2003), myocyte hypertrophy, interstitial fibrosis (Wang et al 2006), and decreased systolic function in the presence of a diastolic dysfunction. More specifically with the heart, intravenous administration of isoproterenol induces left ventricular hypertrophy (Udelson et al 1989). While little correlations have been made between diabetes and its effect on the lungs, it is important to reference the lungs in this thesis because of the abundant expression of beta-adrenergic receptors (Frishman 2003).

Desensitization of beta-adrenergic receptors in the lung can induce lung injury (Kabir et al 2009). Diabetes also affects the kidney producing diabetic nephropathy or Kimmelstiel-Wilson syndrome (Berkman \& Rifkin 1973), which is characterized by angiopathy of capillaries in the kidney glomeruli, leading to kidney dysfunction. Diabetes affects the body in numerous detrimental ways and affects other systems in the body, importantly the nervous system.

\section{Autonomic Nervous System Signaling: Adrenergic Receptors}

The autonomic nervous system, a part of the peripheral nervous system, is composed of two subsystems, parasympathetic and sympathetic nervous systems (Grub et al 1999). Diabetes can induce autonomic neuropathy. In this disease, nerves are damaged producing altered blood pressure, heart rate, and digestion (Benarroch et al 
1993). In diabetic neuropathy, there is a reduction of motor and sensory nerve conduction (Ferrnyhough \& Schmidt 2002) resulting in reduced blood flow to the limbs. The constant firing of nerves in the limb causes tingling in their limbs and eventually loss of total function and possibly amputation due to decreased or no blood flow (Said 2007).

In the eye, the sympathetic nerves have been shown to influence retinal function and diabetic retinopathy (Steinle \& Smith 2002; Wiley et al 2005). In the past, it was believed that sympathetic nerves do not innervate the retina (Laties 1966); however, it was later shown that sympathetic nerves do innervate the retina (Furukawa 1987). It was also shown that stimulation of beta-adrenergic receptors on endothelial cells increases cAMP production (Daniel et al 1987). Further, Burnstock et al (1990) revealed that sympathetic nerves were altered in diabetes. Following this, Wiley et al (2005) showed that loss of sympathetic nerves influenced basement membrane thickness and induced pericyte loss, both complications of diabetic retinopathy. These data findings suggest that beta-receptor stimulation in the retina may slow the progression of diabetic retinopathy.

Since then, the influence of beta-adrenergic receptor stimulation on diabetic retinopathy has and is still being investigated in our lab. Specifically, stimulation of beta-adrenergic receptors on Müller and retinal endothelial cells (REC) with Compound $49 \mathrm{~b}$ resulted in the down regulation of vascular and neuronal markers of diabetic retinopathy and restoration of normal beta-adrenergic receptor signaling (data in submission).

\section{Beta-Adrenergic Receptors: The Retina}

Current studies in our lab have shown that Müller cells possess $\mathrm{B}_{1}$ (Walker \& Steinle 2007) and $\mathrm{B}_{2}$-adrenergic receptors subtypes, while REC possess $\mathrm{B}_{1}$ and $\mathrm{B}_{3}$-adrenergic receptor subtypes (Steinle \& Smith 2002). Stimulation of the beta-adrenergic receptors on the above-mentioned cell types elicited beneficial effects in the retina, such as reductions in inflammatory and apoptotic markers.

\section{Hypotheses of Diabetic Retinopathy}

Data has shown that beta-adrenergic receptor stimulation may be beneficial to the retina (Walker \& Steinle 2007; Williams \& Steinle 2009), however the exact mechanism by which this occurs is not well known. To generate a possible treatment for diabetic retinopathy, it was necessary to understand the cellular signaling mechanism by which a beta-adrenergic receptor agonist modulates components of the disease. There are numerous biochemical mechanisms that can help explain the progression of diabetic retinopathy (Figure 2-2), which include inflammation, reactive oxygen species formation, apoptotic death of retinal cells, and altered insulin production (Klein et al 1995). 


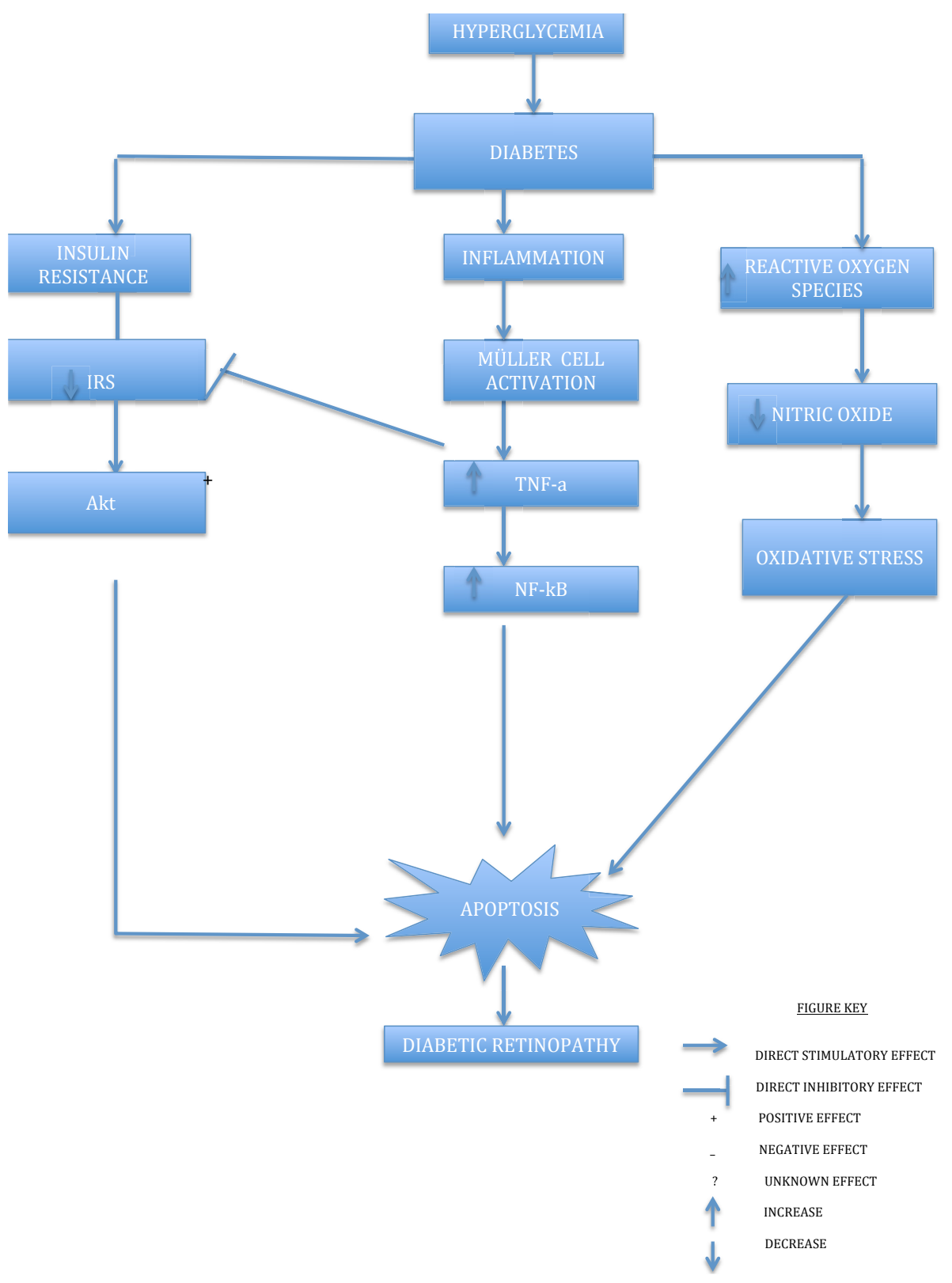

Figure 2-2. Hypothesis of Diabetic Retinopathy. 
As stated previously, activation of the beta-adrenergic receptor induces activation of PKA, which in turn activates downstream signaling molecules (Vassilatis et al 2003).

It is well understood that in diabetes insulin production is reduced. In the beta cell of the pancreas, activation of PKA triggers insulin secretion (Gao et al 2002). It also has been shown that insulin signaling is up-regulated post stimulation with isoproterenol, a non-selective beta-adrenergic receptor agonist (Jiang et al 2010). Specifically, isoproterenol was shown to increase insulin receptor substrate-1 (IRS-1), which in turn activates Akt, and reduces cleavage of caspase 3. Insulin signaling is however inhibited at IRS-1 in the presence of TNF- $\alpha$, an inflammatory marker (van den Oever et al 2010). TNF- $\alpha$ activation, in addition to altering insulin signaling, is also involved in apoptosis in the retina.

The inflammatory component of diabetic retinopathy is a result of increased production of inflammatory markers. Specifically, TNF- $\alpha$ and interleukin beta (IL-1B) are up regulated in the disease state (Chen et al 2005). IL-1B is a pro-inflammatory marker, which mediates TNF- $\alpha$ activation (Kamangar et al 2006). Multiple cell types in the body, such as mast cells, neuronal tissue, and endothelial cells, produce TNF- $\alpha$ (Delair et al 2009). TNF- $\alpha$ has been shown to induce apoptotic cell death and inflammation (Locksley et al 2001). TNF- $\alpha$ binds to the tumor necrosis factor-receptor (TNFR), and induces cleavage of caspase 3,8, leading to cell death. Because TNF- $\alpha$ increases insulin resistance (Kamangar et al 2006), leading to a decrease in Akt, it is necessary to investigate production of TNF- $\alpha$ in these studies.

Increased oxidative stress is widely accepted as an underlying factor in the progression and development of the complications associated of diabetic retinopathy (Maritim et al 2002). Glucose oxidation results in the formation of reactive oxygen species, mainly peroxynitrite radicals formed after superoxide radicals interact with nitric oxide. Free radicals can also be formed via formation of advanced-glycation end products (AGEs) (Cusick et al 2002). AGEs-induced reactive oxygen species formation also activates NF-kB (nuclear factor kappa-light chain-enhancer of activated B cells), a transcriptional factor that enhances nitric oxide formation (Ziyun et al 2007; Kim et al 2010). The constitutive NF-kB also regulates anti-apoptotic genes and inhibition of NF-kB has been shown to induce cellular apoptosis (Kim et al 2010). Contrastingly, NF-kB also regulates pro-inflammatory gene expression and synthesis of cytokines such as TNF- $\alpha$ and IL-1B and therefore possesses pro-apoptotic properties as well (Tak and Firestein 2001).

As stated, apoptosis is also a component of diabetic retinopathy and it is likely the final step in disease progression at the cellular level. Apoptosis of key retinal cells can lead to cell loss in the retina and blindness. One important family of cysteine proteases, the caspase family, plays an essential role in cell death or apoptosis (Lavrik et al 2005). This family of proteases exists in the pro-form, and is regulated post-transcriptionally. There are many key proteins that are involved in apoptosis such as cytochrome c and Bcl-2, which activate caspase 9, and Fas (van den Oever et al 2010). It has been reported that diabetes induces apoptosis in the eye via caspase 3 activation (Mohr et al 2002). It 
has also been shown that retinal ganglion cells express apoptotic factors such as Fas, Bax, and cytochrome C (Abu El-Asrar et al 2007). Furthermore, it has been shown that treatment with xamoterol, a beta-1 selective agonist, on retinal endothelial cells signals through the Fas ligand pathway to regulate apoptosis (Williams \& Steinle 2009). The above listed factors promote apoptosis and inhibition of these factors may prevent apoptosis, a major contributing factor to progression as a result of diabetic retinopathy.

Continuing our knowledge on beta-adrenergic receptor effects in the retina and potential causes of diabetic retinopathy, we hypothesize that treatment with a beta-adrenergic receptor agonist could prevent changes associated with diabetic retinopathy. By screening various compounds synthesized in-house, we evaluated their ability to reduce changes associated with the disease. The subsequent chapters present two compounds, which were effective at reducing markers of diabetic retinopathy in the rat model, in vivo, and in cell culture, in vitro. 


\section{CHAPTER 3. COMPOUND 12: BETA-ADRENERGIC RECEPTOR SIGNALING BY THE ISOMERS OF ISOPROTERENOL AND LIKE DRUGS IN RETINAL ENDOTHELIAL CELLS AND MÜLLER CELLS}

\section{Introduction}

Thickening of the basement membrane of the capillaries in the retina, loss of pericytes, and formation of microaneurysms characterize diabetic retinopathy (Frank 2004). Although laser photocoagulation surgery is the primary treatment of the disease, the associated risks including peripheral vision loss and cataract formation (Abu El-Asrar et al 2007) impose a need for additional therapeutic options. Müller cells and REC are involved in the pathogenesis of diabetic retinopathy. Müller cells serve as supporting glial cells of the retina, and REC are decreased as the disease progresses, ultimately leading to blindness (Williams \& Steinle 2009).

We have previously shown that the loss of sympathetic neurotransmission leads to increased inflammatory marker levels and apoptosis of photoreceptors (Steinle 2007). We have also demonstrated that retinal Müller cells possess both beta- 1 and beta-2adrenergic receptors (Williams \& Steinle 2009), while retinal endothelial cells possess beta-1 and beta-3-adrenergic receptors (Walker \& Steinle 2007). Our results showed that treatment with $10 \mathrm{uM}$ isoproterenol, a non-selective beta-adrenergic receptor agonist or 10uM xamoterol, a selective beta-adrenergic receptor agonist on Müller and REC cells reduced apoptosis in both cell types via a reduction of cleaved caspase 3 levels in vitro (Walker \& Steinle 2007; Williams \& Steinle 2009). Because diabetic retinopathy has characteristics of inflammation (Joussen et al 2009), we have data indicating that TNF- $\alpha$ levels were reduced after isoproterenol treatment over an 8-month period (Jiang et al 2010). However, isoproterenol produced remodeling of the left ventricle when administered topically in the eye, demonstrating negative responses of systemic exposure (Heather et al 2009). We sought to develop novel derivatives of isoproterenol and to evaluate their ability to reduce the cleavage of caspase 3 (a marker of apoptosis) and TNF- $\alpha$ levels (a marker of inflammation) in the retina. Isoproterenol has one asymmetric center and exists as enantiomers (Figure 3-1).

Although the two optically active enantiomers have same achiral physical properties in general, discrepancies in physiological activities are quite often observed between the two enantiomers. Therefore, the development of a single enantiomeric compound instead of racemic mixtures is strongly encouraged in new drug development.

\section{Compound Synthesis}

In collaboration with Dr. Duane Miller, our chemist Jayaprakash Pagadala, enantioselective synthesis of catecholamines was carried out by using the Sharpless asymmetric dihydroxylation. We observed S-1 to be significantly less potent than the 

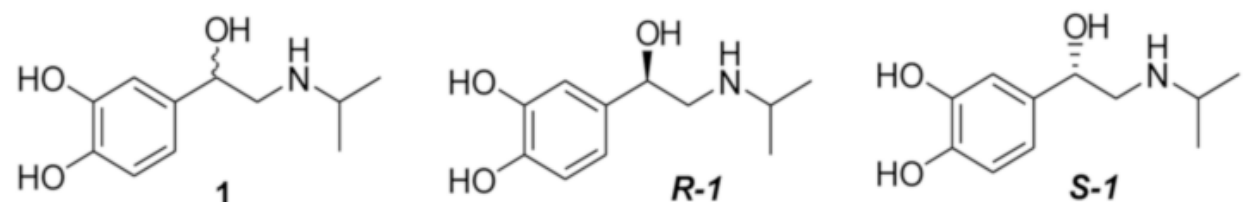

Figure 3-1. Chemical Structures of Isoproterenol.

From left to right: Racemic isoproterenol, R-1 isomer of isoproterenol, and S-1 isomer of isoproterenol corresponding R-1 after statistical analyses. Compounds were then synthesized with the chemical backbone of the R-1 isomer. 
corresponding R-1 after statistical analyses. Compounds were then synthesized with the chemical backbone of the R-1 isomer.

\section{Materials and Methods}

REC were purchased from Cell Systems Corporation (CSC) (Kirkland, WA) and cultured in CSC medium grown in high glucose $(25 \mathrm{mM})$. Media was supplemented with $20 \%$ fetal bovine serum (FBS) and antibiotics. Müller cells were kindly provided by Dr. Vijay Sarthy, Northwestern University) were cultured in high glucose $(25 \mathrm{mM})$ in Dulbecco's Modified Eagle's Medium (DMEM) and supplemented with 10\% FBS and antibiotics. Twenty-four hours before treatment with compounds R-1, S-1, 10, 11, and 12 , Müller cells and REC were cultured in high glucose medium with antibiotics and $0 \%$ FBS to induce serum starvation.

Dishes of each cell type were cultured in only high glucose to serve as non-treated controls. Dishes from each cell type for each dosage were cultured in high glucose and treated with $50 \mathrm{nM}, 100 \mathrm{nM}$, and $10 \mathrm{uM}$ dosages of each of the 5 compounds. REC were treated for 30- and 60-minutes, while Müller cells were treated for1-and 24-hours. REC time points were based upon data with xamoterol (Figure 3-2), which was shown to be most effective at reducing apoptotic markers after 30-and 60-minutes of stimulation (Williams \& Steinle 2009). Müller cell time points were based upon data with isoproterenol (Walker \& Steinle 2007). Retinal lysates from Müller and REC were assayed using a human TNF- $\alpha$ ELISA assay (Thermo Scientific) (Rockford, IL) and cleaved caspase 3 ELISA kit (Cell Signaling) (Danvers, MA).

\section{Results}

Apoptosis of REC is a factor in the early phases of diabetic retinopathy. Therefore, we used decreased cleavage of caspase 3 as a marker of reduced apoptosis in cells cultured in high glucose. Compounds R-1, 11, and 12 significantly decreased caspase 3 levels in REC (Figure 3-3), while 10 and S-1 did not significantly decrease caspase 3 levels after treatment. Compound 12 significantly reduced caspase 3 levels at the $50 \mathrm{nM}$ and $100 \mathrm{nM}$ dosages within the 30 -and 60 -minute time points, which is lower than isoproterenol. To evaluate inflammatory marker levels in culture, TNF- $\alpha$ levels were evaluated. We found that Compound 12 decreased both TNF- $\alpha$ and caspase 3 levels in REC while Compound 10 increased TNF- $\alpha$ levels (Figure 3-4). TNF- $\alpha$ levels in REC were unchanged after treatment with R-1, S-1, and Compound 11 (not shown). On the other hand, cleaved caspase 3 levels in Müller cells (Figure 3-5) were not significantly decreased after treatment with R-1, S-1, 10, 11, or 12. The non-specific beta-adrenergic receptor agonist R-1 and S-1 isomers decreased TNF- $\alpha$ inflammatory levels in Müller cells (Figure 3-6), consistent with preliminary results from isoproterenol; however, R-1 decreased TNF- $\alpha$ at the $50 \mathrm{nM}$ and $100 \mathrm{nM}$ dosages, which is lower than the effective dose of isoproterenol. All analogs failed to significantly decrease TNF- $\alpha$ in Müller cells. Based upon these results, Compound 12 decreased both markers in REC only. 


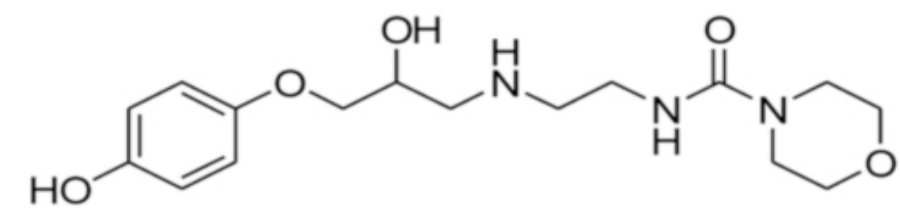

Figure 3-2. Chemical Structure of Xamoterol. 

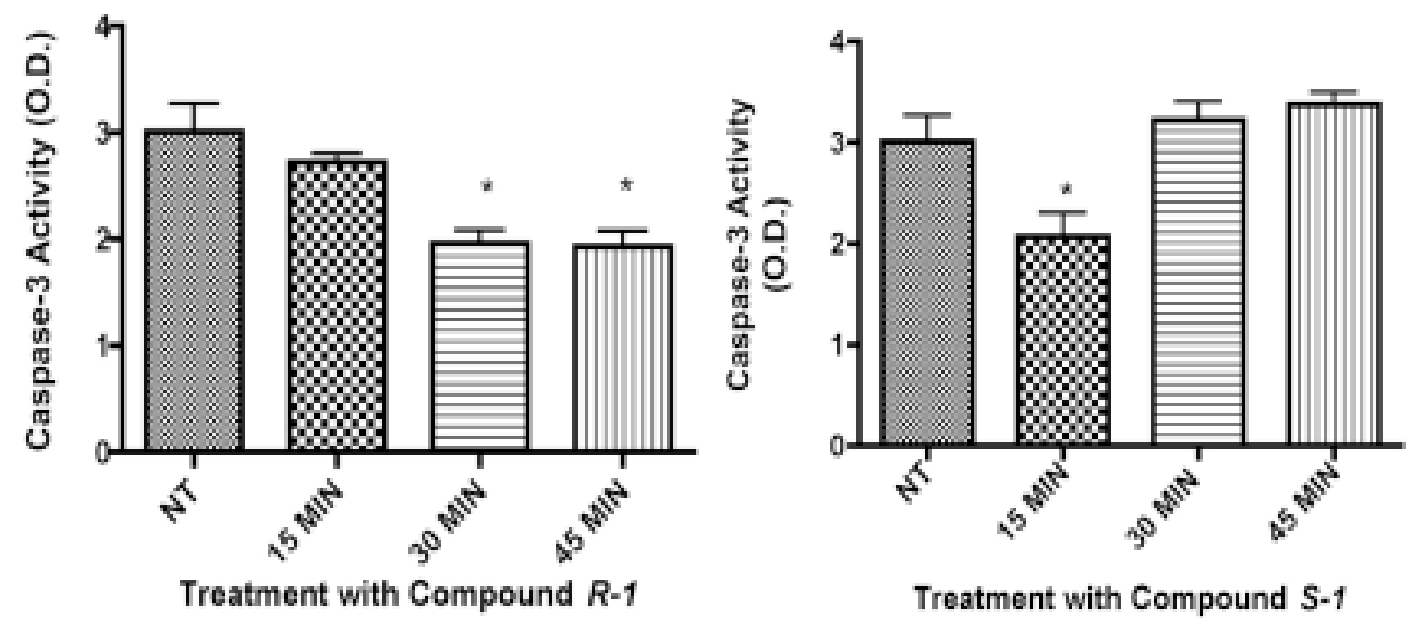

Treatment with Compound S-1
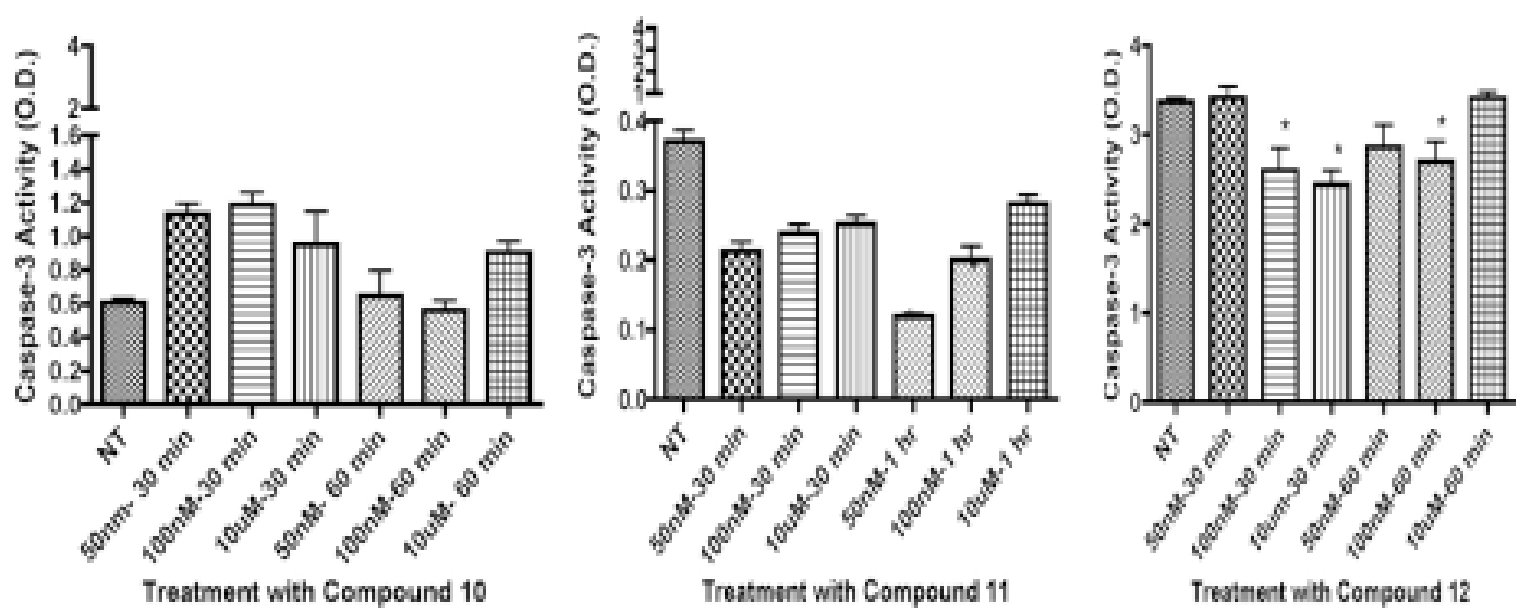

Figure 3-3. Cleaved Caspase 3 Results in REC for Compounds R-1, 10, 11, and 12.

Graphs show results of caspase 3 ELISA. For isomers of isoproterenol, cells were treated at $10 \mathrm{uM}$ at 15-, 30-, and 45-minutes. Analogue compounds 10,11, and 12 were treated at $50 \mathrm{nM}, 100 \mathrm{nM}$, and $10 \mathrm{uM}$ at 30 -minutes and 1-hour time points. Treatment groups were compared to not-treated (NT) controls. ${ }^{*} \mathrm{P}<0.05$ vs. NT. 

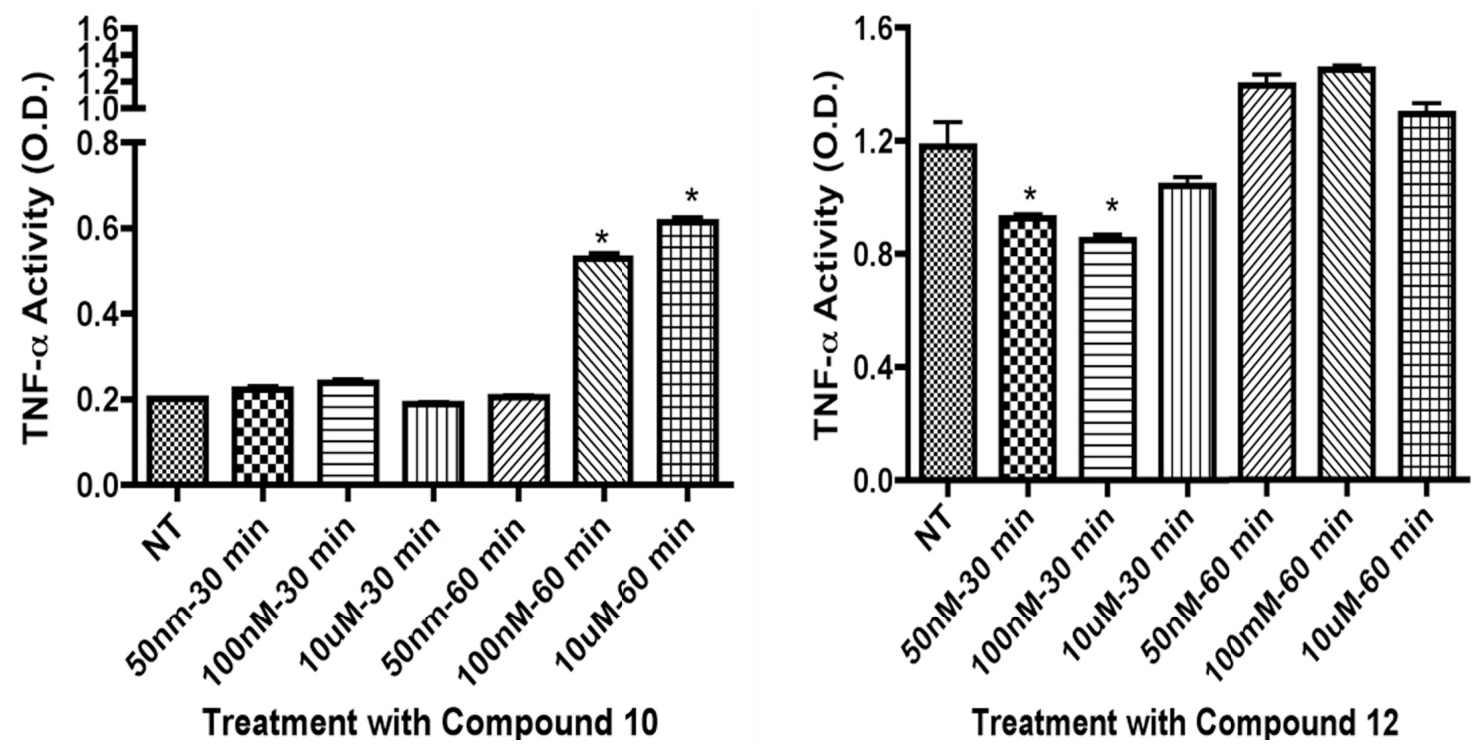

Figure 3-4. TNF- $\alpha$ Activity Results in REC for Compounds 10 and 12.

Analogue compounds 10 and 12 were treated at $50 \mathrm{nM}, 100 \mathrm{nM}$, and $10 \mu \mathrm{M}$ at 30 -minutes and 1-hour time points. Treatment groups were compared to not-treated (NT) controls. ${ }^{*} \mathrm{P}<0.05$ vs. NT. 


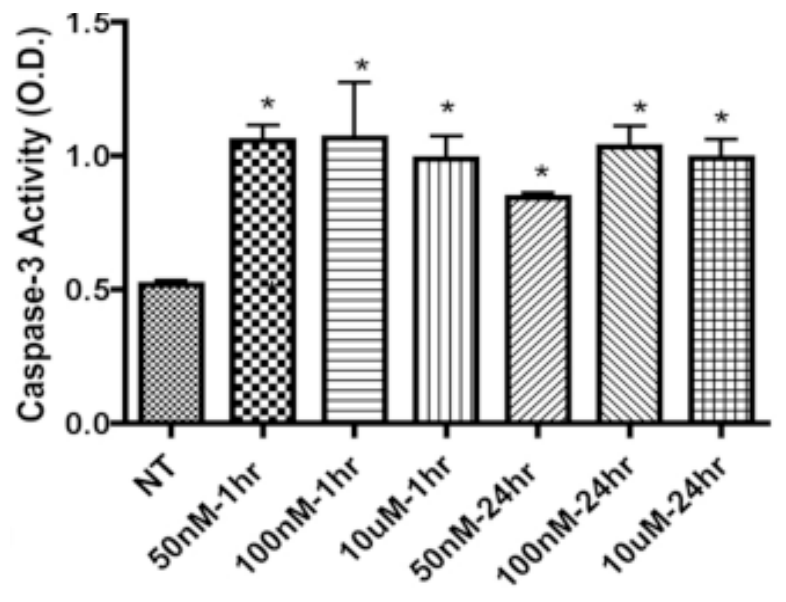

Treatment with Compound $R-1$

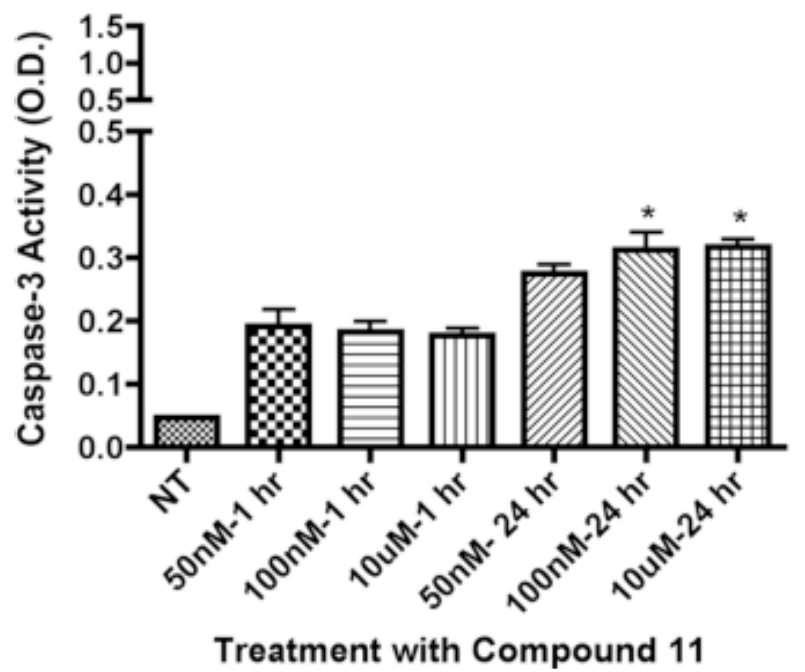

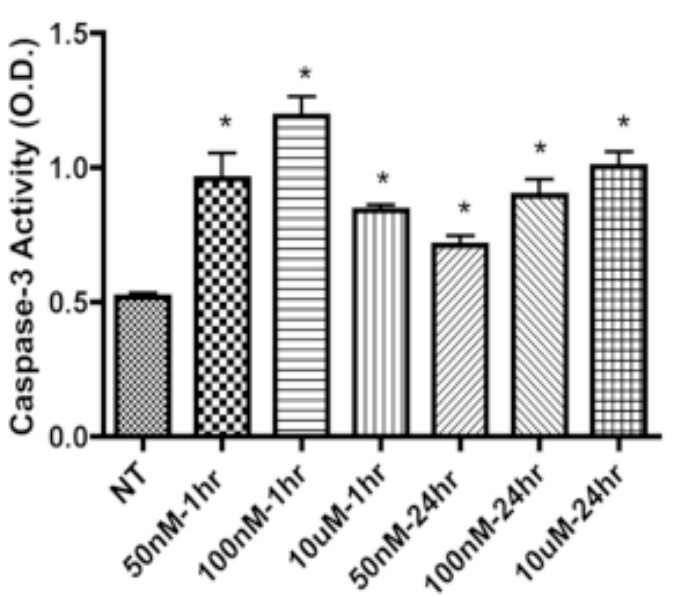

Treatment with Compound S-1

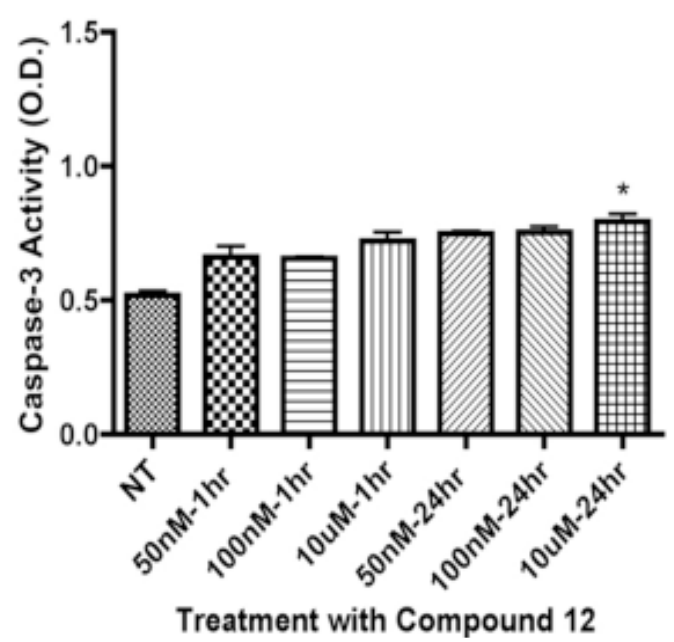

Figure 3-5. Cleaved Caspase 3 Results in Müller Cells for Compounds R-1, S-1, 11 , and 12.

Compounds R-1, S-1, 11 and 12 were treated at 50nM, 100nM, and 10uM at 1-and 24hour time points. Treatment groups were compared to not-treated (NT) controls. ${ }^{*} \mathrm{P}<0.05$ vs. NT. 

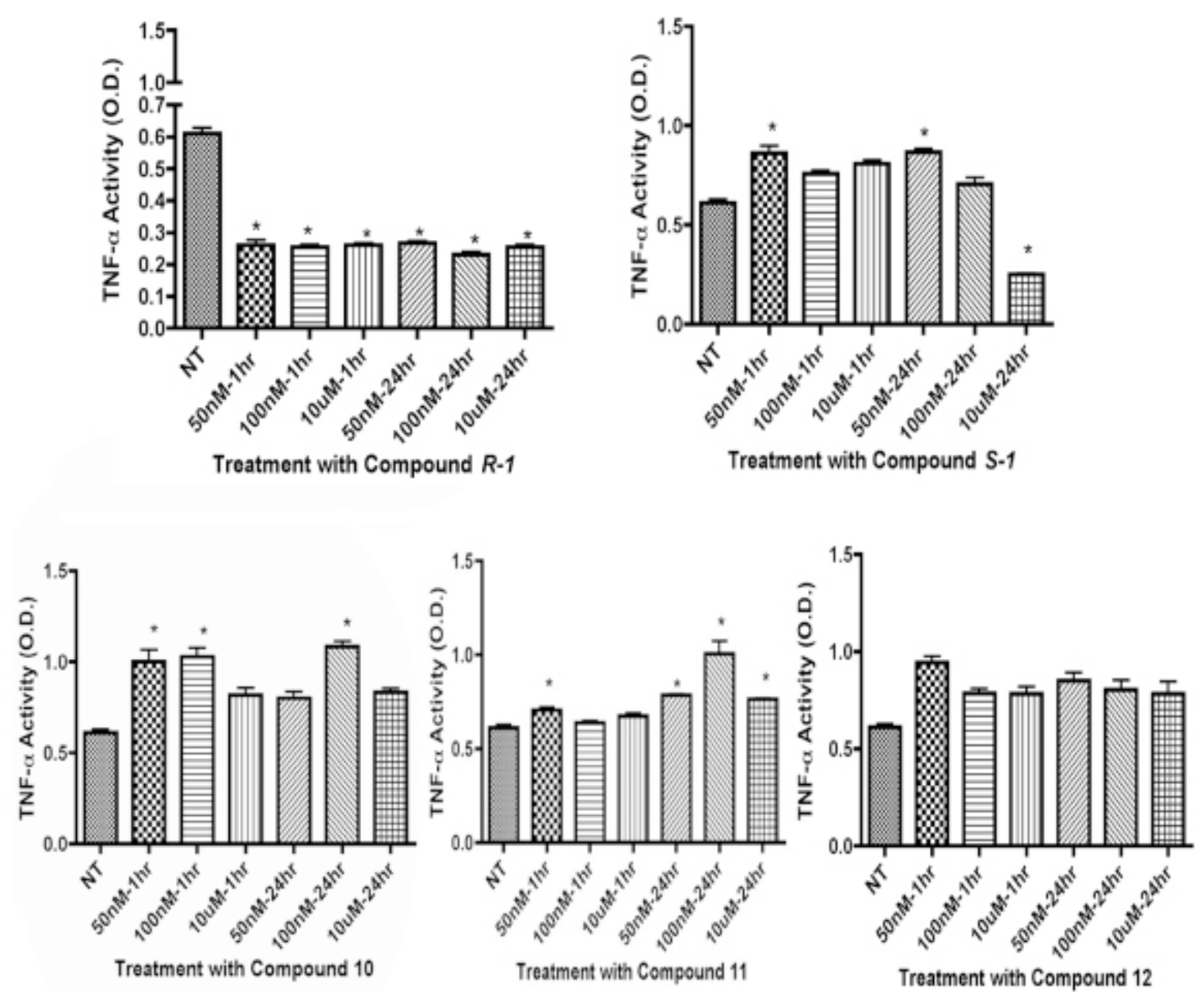

Figure 3-6. TNF- $\alpha$ Activity Results in Müller Cells for Compounds R-1, S-1, 10, 11 and 12.

Analogue compounds R-1, S-1, 10, 11, and 12 were treated at $50 \mathrm{nM}, 100 \mathrm{nM}$, and $10 \mathrm{uM}$ at 1- and 24-hour time points. Treatment groups were compared to not-treated (NT) controls. ${ }^{*} \mathrm{P}<0.05$ vs. NT. 


\section{Discussion}

Screening of our novel compounds showed diverse receptor activity between REC and Müller cells. Preliminary experiments with isoproterenol showed it to be effective at reducing caspase 3 in both cell types and TNF- $\alpha$ in REC (Williams \& Steinle 2009). We observed that R-1 significantly reduced caspase 3 levels in REC and in Müller cells, while S-1 did not affect caspase 3 or TNF- $\alpha$ activity in REC. S-1 did show a decrease in TNF- $\alpha$ activity in Müller cells but R-1 was observed to be more effective, as it decreased TNF- $\alpha$ levels at lower dosages. Identifying the R-isomer as the more active enantiomer of isoproterenol allowed for formulation of more specific derivatives of the R-isomer.

We reported that xamoterol, a selective beta-1-adrenergic receptor agonist, was able to significantly reduce caspase 3 and TNF- $\alpha$ levels in REC (Williams \& Steinle 2009). We also reported that beta-2 adrenergic receptor selectivity needed to be maintained to stimulate Müller cells (Walker \& Steinle 2007). We hypothesized that the morpholine moiety accounts for xamoterol's high selectivity for beta-1 adrenergic receptors, and we therefore designed structural catecholamine derivatives of isoproterenol and attached the morpholine moiety to test the ability of these analogues to reduce cleavage of caspase 3 and TNF- $\alpha$ activity. The structural analogues, compounds 10, 11, and 12 had various effects in both cell types. We observed that Compound 10 were not able to significantly decrease caspase 3 cleavage or TNF- $\alpha$ in REC or Müller cells. Compound 11 was able to decrease cleaved caspase 3 levels in REC but was not effective in Müller cells, while 12 was able to decrease both caspase 3 and TNF- $\alpha$ in REC.

Compound 12 effectively decreased both inflammatory and apoptotic levels in REC and a significant decrease was not observed in Müller cells. These findings suggested that continued synthesis of isoproterenol analogues could present new drug candidates able to reduce apoptotic and inflammatory markers, making them useful therapeutic agents in the treatment of diabetic retinopathy.

\section{Conclusion}

We have shown that single enantiomer R-1 is more potent than the S-1enantiomer of isoproterenol. Due to its effectiveness over S-1, the analogues of R-1 were formulated and Compound 12 was the only analogue that significantly decreased both apoptotic and inflammatory levels in REC cells. In addition to the findings on 12, the data using R-1 also suggests that there is a separation of the responsiveness to specific classes of beta-adrenergic receptors. REC possess beta- 1 and beta- 3 adrenergic receptors, while Müller cells possess beta- 1 and beta-2-adrenergic receptors, where the beta- 1 and beta- 2 adrenergic receptor is the dominant type. These findings suggest that Compound 12 is the most effective analogue in its ability to decrease both inflammatory and apoptotic levels in vitro using REC. This decrease was observed at a lower dosage than the effective dose of isoproterenol and it did not bind to beta-adrenergic receptors, which indicates a different mechanism for Compound 12 as compared. 


\section{CHAPTER 4. COMPOUND 49B: A NOVEL BETA-ADRENERGIC RECEPTOR AGONIST IN THE TREATMENT OF DIABETIC RETINOPATHY}

Although Compound 12 was found to be effective in REC, we sought to screen more beta-adrenergic receptor agonists due to the inability of Compound 12 to effectively prevent high-glucose induced changes in Müller cells. Compounds were analyzed using ELISA assays for their ability to reduce TNF- $\alpha$ and caspase 3 in REC and Müller cells. Data obtained from these screenings showed that of the compounds tested, Compound $49 \mathrm{~b}$ effectively prevented and delayed the onset of changes associated with diabetic retinopathy.

\section{Introduction}

Data in the field has shown that diabetic retinopathy is the leading cause of blindness in American adults (Frank 2004). Some of the changes noted in early diabetic retinopathy include thickening of the basement membrane, pericyte loss, degenerate capillary formation, and the loss of cell number in the ganglion cell layer of the retina (Wiley et al 2005). In addition to retinal changes common to diabetes, sympathetic nerves are also damaged following chronic hyperglycemia (Burnstock 1990). Work in the dopamine beta hydroxylase knockout mice demonstrated that loss of norepinephrine produced retinal changes similar to those noted in diabetic retinopathy (Steinle et al 2009). This finding suggests that maintenance of adrenergic receptor signaling may be beneficial to the retina and prevent neuronal and vascular damage. Indeed, previous work in our lab has shown that daily administration of $50 \mathrm{mM}$ marker levels, as well as the histological changes in the diabetic retina (Jiang et al 2010). Isoproterenol also maintained normal electrical activity of the retina, while increasing Akt and insulin receptor phosphorylation in diabetic rats compared to control values. Unfortunately, previous studies also showed that $50 \mathrm{mM}$ topical isoproterenol led to increased systemic circulation of the drug, which induced detrimental cardiovascular remodeling. We therefore developed a novel beta-adrenergic receptor agonist, Compound 49b (Figure 4-1) to evaluate its ability to reduce markers of diabetic retinopathy without causing cardiovascular remodeling.

\section{Materials and Methods}

We have previously demonstrated that isoproterenol can prevent the neuronal and vascular changes in the diabetic rat retina (Jiang et al 2010). While isoproterenol was a potent beta-adrenergic receptor agonist, topical administration caused left ventricular remodeling, suggesting that isoproterenol enters into the systemic circulation. To avoid these deleterious side effects, we synthesized Compound $49 \mathrm{~b}$ to mimic the structure of isoproterenol. Compound $49 \mathrm{~b}$ has both beta- 1 and beta- 2 adrenergic receptor specificity but also has a trimethyl group opposite the catechol. 


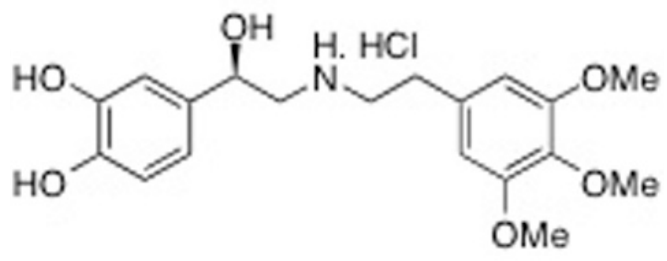

Figure 4-1. Structure of Compound 49b. 
Structurally, Compound $49 \mathrm{~b}$ consists of an N-substituent p-methoxyphenyl ring, which allows $\pi-\pi$ electron interactions with the catechol aromatic ring to lock in the conformation. The stability of this conformation limits the conformational and orientational freedom within the beta-adrenergic receptor-binding pocket. These conformational interactions increase the activity of Compound $49 \mathrm{~b}$ in comparison to isoproterenol.

REC were purchased from Cell Systems Corporation (CSC) (Kirkland, WA) and maintained in CSC media supplemented with $20 \%$ FBS and antibiotics. Only primary cells between passages 2-4 were used for all experiments. Cells were grown in high glucose medium $(25 \mathrm{mM})$ and once cells reached $\sim 80 \%$ confluency, they were placed into high glucose medium without FBS to induce serum starvation for 18-24 hours. Previous data suggested that treatment with beta-adrenergic receptor agonists for 30- and 60 -minutes produced a significant response to both cleaved caspase 3 and TNF- $\alpha$ level analyses (Williams \& Steinle 2009), thus these time points were used for studies. Cells were treated with Compound $49 \mathrm{~b}$ at the $50 \mathrm{nM}, 100 \mathrm{nM}$, and $10 \mathrm{uM}$ dosages for 30 - and 60-minutes. For all experiments, non-treated cells served as controls.

Müller cells were kindly provided by Dr. Vijay Sarthy (Northwestern University) were thawed and cultured in DMEM medium in high glucose $(25 \mathrm{mM})$ conditions. Medium was supplemented with 10\% FBS and antibiotics. Once cells reached $\sim 80 \%$ confluency, they were placed into high glucose medium without FBS to induced serum starvation for 18-24 hours. Müller cells were treated with Compound $49 \mathrm{~b}$ at the 1-and 24-hour time points following serum starvation. For consistency with the REC data, Müller cells were treated at $50 \mathrm{nM}, 100 \mathrm{nM}$, and $10 \mathrm{uM}$ for all compounds. For all experiments, some cells remained untreated as controls.

To screen the ability of Compound $49 \mathrm{~b}$ to reduce the of cleavage of caspase 3 and TNF- $\alpha$ levels in vitro, cleaved caspase 3 ELISA assay (Cell Signaling) (Danvers, MA) and TNF- $\alpha$ ELISA assay (Thermo Scientific) (Rockford, IL) analyses were carried out according to the manufacturer's protocol, except that equal protein amounts were loaded into each well to allow for calculations using optical density values. Both REC and Müller cells were treated with each compound at the same dosages and time points. All analyses were done and compared to non-treated controls.

To determine the optimal dose in vivo in diabetic rats, male Lewis rats were purchased from Charles River at 8-weeks of age. To induce diabetes, a single injection of $60 \mathrm{mg} / \mathrm{kg}$ streptozotocin dissolved in citrate buffer (Fisher Scientific) (Pittsburgh, PA) was administered. Control rats were injected with citrate buffer only. Rat glucose levels were tested 2 days following the injection, with glucose levels $>250 \mathrm{mg} / \mathrm{dL}$ accepted as diabetic. To determine whether topical application of Compound $49 \mathrm{~b}$ reaches the retina and elicits a response common to beta-adrenergic receptor stimulation, multiple doses of Compound $49 \mathrm{~b}$ were analyzed for their ability to increase PKA activity in the diabetic rat retina. Two groups of animals were used: a non-diabetic control group (Ctrl) and a diabetic + treatment group $(\mathrm{Diab}+49 \mathrm{~b})$. Diabetes was induced for 2 months prior to any treatments. Animals in both groups were treated with 7 
different doses of Compound 49b (all below the required dose of 50mM for isoproterenol): $1 \mathrm{uM}, 10 \mathrm{uM}, 100 \mathrm{uM}, 1 \mathrm{mM}, 5 \mathrm{mM}, 10 \mathrm{mM}$, and $20 \mathrm{mM}$. After 4-days of topical Compound 49b treatment, animals were anesthetized with ketamine-xylazine cocktail. Retinal lysates from rats in all groups were analyzed using a PKA Activity ELISA (MesaCup PKA Activity ELISA) (Temecula, CA) to quantitate the activation of PKA following Compound 49b stimulation, which would suggest that topical Compound $49 \mathrm{~b}$ reached the retina and elicited a physiological beta-adrenergic receptor stimulation response.

Male Lewis rats were purchased from Charles River at 8 weeks of age. Three groups of rats were used for each of the prevention and delayed treatment groups: non-diabetic ( $\mathrm{Ctrl})$, diabetic, and diabetic $+49 \mathrm{~b}(\mathrm{Diab}+49 \mathrm{~b})$. Rats receiving immediate eye drop therapy were injected with streptozotocin and after one week of injection, rats were characterized as having diabetes once glucose levels were $>250 \mathrm{mg} / \mathrm{dL}$. Diabetic +Compound $49 \mathrm{~b}$ rats began receiving daily topical drops of $1 \mathrm{mM}$ Compound $49 \mathrm{~b}$ on the day glucose levels were measured to be above $250 \mathrm{mg} / \mathrm{dL}$. Diabetic only and control rats received no Compound $49 \mathrm{~b}$.

Another subset of treatment rats were injected and characterized in the same manner as the prevention group, but treatment with $1 \mathrm{mM}$ topical $49 \mathrm{~b}$ began after rats had untreated diabetes for 6-months. All rats in both groups received monthly ERG, blood pressure, intraocular pressure (IOP), and blood glucose and weight measurements. Rats were sacrificed at 2- and 8- months of treatment in the prevention group and after 2- and 6-months of treatment in the delayed treatment group. All animal procedures were approved by the Institutional Animal Care and Use Committee (IACUC) of the University of Tennessee Health Science Center and conform to all guidelines set forth by NIH. Electroretinogram (ERG) analyses were carried out to evaluate the changes in the electrical activity of the retina as we have done previously (Jiang et al 2010). Briefly, rats were dark adapted overnight. ERG responses were recorded from both eyes together using platinum wire corneal electrodes, forehead reference electrode, and ground electrode in the tail. Pupils were fully dilated using 1\% tropicamide solution (Alcon) (Fort Worth, TX). Methylcellulose (Celluvise, Allergan) (Irvine, CA) drops were applied as well to maintain a good electrical connection and body temperature was maintained at $37^{\circ} \mathrm{C}$ by a water-based heating pad. ERG waveforms were recorded with a bandwidth of $0.3-500 \mathrm{~Hz}$ and samples at $2 \mathrm{kHz}$ by a digital acquisition system and were analyzed a custom-built MatLab program. Statistics was done on the mean $\pm \mathrm{SD}$ amplitudes of the a- and b- wave of each treatment group.

Blood pressure (BP) was measured noninvasively monthly using a CODA non-invasive blood pressure machine (CODA Systems,Kent Scientific) (Torrington, CT). Animals were placed on an electrical heated pad and an individual holder consisting of an occlusion cuff and volume pressure recording (VPR) cuff was placed at the base of the tail, allowing systolic BP, diastolic BP, mean BP, heart pulse rate, tail blood volume, and tail blood flow to be measured simultaneously. 
IOP was measured monthly using a tonometer (TonoLab, Colonial Medical Supply) (Franconia, NH). Briefly, the tip of the probe of the tonometer was placed at the cornea of the eye. During measurements, the tip of the probe contacts the cornea six times and gave the IOP reading of that eye. This procedure was carried out in both eyes. Paraffin embedded sections of the retina were stained with toluidine blue for light microscopy and morphometry of retinal thickness as described (Jiang et al 2010). Photomicrographs were assessed for retinal thickness and the number of cells in the GCL was counted using methods previously described (Jiang et al 2010). The thickness of the retina and the cell count were measured using OpenLab software (Improvision) (Lexington, MA).

Retinas from 1 eye of all control, diabetic, and diabetic $+49 \mathrm{~b}$ rats after 8 -months ( 8 months of diabetes) or 6 -months of treatment (12 months of diabetes) were used to count degenerate capillaries in prevention and delayed treatment groups, respectively. The eyes were enucleated, suspended in $10 \%$ buffered formalin for 5 days, and the retina was dissected in 3\% crude trypsin solution (Difco Bacto Trypsin 250) (Detroit, MI). The retinal vascular tree was dried onto a glass slide and stained with hematoxylin-periodic acid-Shiff. Degenerate capillaries were counted and identified as previously described (Jiang et al 2010). Pericyte ghosts are estimated from the prevalence of spaces in the capillary basement membranes, where pericytes have disappeared. Pericyte ghost numbers were determined in multiple mid-retina fields, and reported per 1000 capillary cells (Engerman \& Kern 1994; Kern \& Engerman 1995).

Tissue sections from the heart of control, diabetic, and treated rats at the 8-month of diabetes time point in the prevention treatment groups were analyzed for left ventricle morphology. Tissue was frozen with freezing medium and $20 \mathrm{um}$ sections were obtained via cryostat sectioning. Sections were fixed to glass slides and stained with Pico Red collagen stain. Pictures were taken at 400x using a Retiga camera attached to a Nikon Biophot light microscope with Qcapture software (QImaging) (Canada).

Retinal lysates from one eye of all rats were assayed for protein levels of TNF- $\alpha$ (Thermo Scientific) (Rockford, IL) and cleaved caspase 3 (Cell Signaling) (Danvers, MA) via ELISA assays at 2- and 8-months for prevention and 2- and 6-months for delayed treatment rats. ELISA assays were carried out similar to in vitro experiments.

Protein activity levels were also determined by Western blot analysis with the following antibodies: total insulin receptor beta (1:500, Cellular Signaling) (Danvers, MA), phosphorylated insulin receptor beta (Tyr 1150/1151, 1:500, Cellular Signaling) (Danvers, MA), total Akt (1:500, Cellular Signaling) (Danvers, MA), phosphorylated Akt (Ser ${ }^{473}, 1: 500$, Cellular Signaling) (Danvers, MA), total IRS-1 (1:500 Cellular Signaling) (Danvers, MA), and phosphorylated IRS-1 ( $\operatorname{Ser}^{307}, 1: 500$ Cellular Signaling) (Danvers, MA).

Statistical analysis was done to compare control, diabetic, and diabetic $+49 \mathrm{~b}$ using a Kruskal-Wallis analysis, with Dunn's test post-hoc analyses. $\mathrm{P}<0.05$ was determined as significant. 


\section{Results}

Daily topical administration of $1 \mathrm{mM}$ Compound $49 \mathrm{~b}$ did not affect body weight or blood glucose levels at 8-months time points (Table 4-1). Body weight and blood glucose levels showed little variation between the 2 - and 8-month time points. There was also no observed effect on blood pressure or intraocular pressure following Compound $49 \mathrm{~b}$ treatment for 8-months. In the delayed treatment studies, there were no observed effects on body weight, blood pressure, intraocular pressure, or blood glucose measurement in rats receiving treatment (Table 4-2).

We have previously demonstrated that isoproterenol could decrease cleaved caspase 3 levels in REC and Müller cells cultured in hyperglycemic conditions at a dose of 10uM (Walker \& Steinle 2007). However isoproterenol induced cardiovascular changes (Grubb et al 1999); therefore, we developed a novel beta-adrenergic receptor agonist, Compound $49 \mathrm{~b}$ to evaluate its ability to reduce markers of diabetic retinopathy in addition to reducing cardiovascular remodeling. Our data indicated that there was no increase in diabetes-induced changes to the heart.

Caspase 3 is a pro-apoptotic protein whose cleavage and activation indicates cell death (Salvesen 2002). Treatment with Compound 49b at the 50nM concentration significantly decreased caspase 3 levels in REC at the 30-minute time point and in Müller cells at the 24-hour time point (Figure 4-2). These results show that Compound 49b is able to decrease a key marker of cell apoptosis in vitro.

Because inflammation is a characteristic of diabetic retinopathy (Joussen et al 2009), protein levels of TNF- $\alpha$ were analyzed in REC and Müller cells cultured in high glucose. Compound $49 \mathrm{~b}$ treatment significantly reduced TNF- $\alpha$ levels after 1 -hour at the $50 \mathrm{nM}$ concentration in REC and at the 50nM concentration in Müller cells. These results suggest that Compound $49 \mathrm{~b}$ is able to significantly reduce inflammatory markers in vitro in hyperglycemic conditions.

To determine the optimal dose and time point for Compound $49 \mathrm{~b}$ administration in vivo, rats were treated with streptozotocin $(60 \mathrm{mg} / \mathrm{kg})$ to induce diabetes. After 2 -months of diabetes, rats were treated for 4 days with varying doses of Compound $49 \mathrm{~b}$ ranging from $1 \mathrm{uM}$ to $20 \mathrm{mM}$ to determine the optimal dose. Stimulation of beta-adrenergic receptors can increase cAMP accumulation, leading to PKA activation and CREB phosphorylation (Williams \& Ford 2001). PKA was therefore used as markers to show that Compound $49 \mathrm{~b}$ actually reached the retina and elicited a response the appropriate cellular response. We found that the $1 \mathrm{mM}$ Compound $49 \mathrm{~b}$ showed the highest increase in PKA activity in comparison with the other administered doses (Figure 4-3). The $1 \mathrm{mM}$ concentration treatment was used for all subsequent experiments.

A-wave, b-wave amplitude, and oscillatory potential (OP) amplitude were measured monthly in each group via ERG analysis. Data was obtained from animals at 2-, 6-, and 8-months of diabetes for prevention group and at 6-, 8-, and 12-months in 
delayed treatment group. While there was little difference seen between ERG amplitudes of control rats and those receiving $1 \mathrm{mM}$ Compound $49 \mathrm{~b}$ at 2-and 8-months, untreated Table 4-1. Prevention Study Vital Measurements.

\begin{tabular}{lllccc}
\hline Groups & $\begin{array}{c}\text { Body Weight } \\
(\mathbf{g})\end{array}$ & $\begin{array}{c}\text { Blood } \\
\text { Glucose } \\
(\mathbf{m g} / \mathbf{d L})\end{array}$ & $\begin{array}{c}\text { Blood } \\
\text { Pressure: } \\
\text { Systolic }\end{array}$ & $\begin{array}{c}\text { Blood } \\
\text { Pressure: } \\
\text { Diastolic }\end{array}$ & $\begin{array}{c}\text { Intraocular } \\
\text { Pressure }\end{array}$ \\
\hline Control & $506.7 \pm 37.5$ & $132.7 \pm 7.3$ & $100.0 \pm 10.9$ & $77.0 \pm 9.4$ & $8.92 \pm 1.52$ \\
Diabetic & $273.1 \pm 40.5^{* *}$ & $724.6 \pm 39.2^{*}$ & $115.9 \pm 14.1$ & $87.8 \pm 13.7$ & $7.19 \pm 1.05^{*}$ \\
Diabetic & $248.7 \pm 8.3^{* *}$ & $695.8 \pm 62.2^{* * *}$ & $104.8 \pm 13.6$ & $81.2 \pm 14.1$ & $8.08 \pm 1.17$ \\
$+49 \mathrm{~b}$ & & & & & \\
\hline
\end{tabular}

Table represents data on the control (Ctrl), Diabetic, and Diabetic $+49 b(\mathrm{Diab}+49 \mathrm{~b})$ for body weight, glucose levels at 2 -and 8 -months of treatment, blood pressure and intraocular pressure. Data is mean \pm SD. ${ }^{*} \mathrm{P}<0.05$ vs. Ctrl. ${ }^{* *} \mathrm{p}<0.01$ vs. Ctrl. ${ }^{* * *} \mathrm{p}<0.001$ vs. Ctrl. 
Table 4-2. Delayed Treatment Study Vital Measurements.

\begin{tabular}{lccccc}
\hline Groups & $\begin{array}{c}\text { Body Weight } \\
(\mathbf{g})\end{array}$ & $\begin{array}{c}\text { Blood } \\
\text { Glucose } \\
(\mathbf{m g} / \mathbf{d L})\end{array}$ & $\begin{array}{c}\text { Blood } \\
\text { Pressure: } \\
\text { Systolic }\end{array}$ & $\begin{array}{c}\text { Blood } \\
\text { Pressure: } \\
\text { Diastolic }\end{array}$ & $\begin{array}{c}\text { Intraocular } \\
\text { Pressure }\end{array}$ \\
\hline Control & $578.0 \pm 23.64$ & $142.6 \pm 18.6$ & $81.6 \pm 6.9$ & $70.4 \pm 1.6$ & $8.92 \pm 1.52$ \\
Diabetic & $283.3 \pm 3.52^{*}$ & $748.7 \pm 3.3^{*}$ & $106.0 \pm 10.5$ & $74.7 \pm 7.7$ & $11.0 \pm 1.9$ \\
Diabetic & $298.7 \pm 45.5^{* * *}$ & $743.0 \pm 11.7^{*}$ & $103.2 \pm 10.6$ & $79.0 \pm 8.8$ & $10.8 \pm 2.2$ \\
$+49 \mathrm{~b}$ & & & & & \\
\hline
\end{tabular}

Table represents data on the control (Ctrl), Diabetic, and Diabetic $+49 b(\mathrm{Diab}+49 \mathrm{~b})$ for body weight, glucose levels, blood pressure and intraocular pressure at 2-and 6-months of treatment with 6-months of pre-existing diabetes. Data is mean $\pm \mathrm{SD}$. ${ }^{*} \mathrm{P}<0.05$ vs. Ctrl. $\mathrm{p}<0.01$ vs. Ctrl. ${ }^{* * *} \mathrm{p}<0.001$ vs. Ctrl. 
REC HG

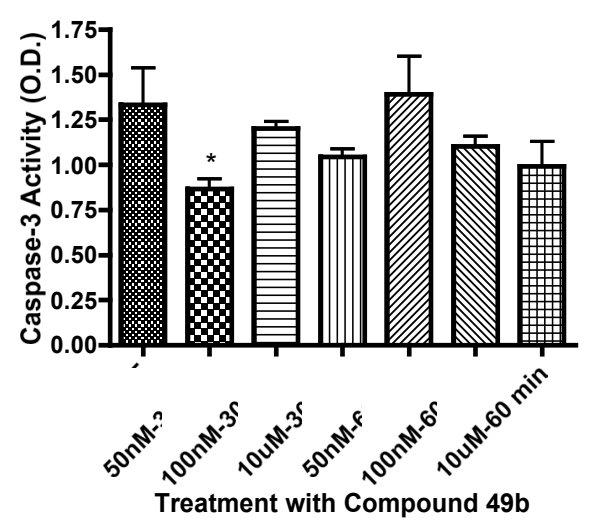

MÜLLER HG

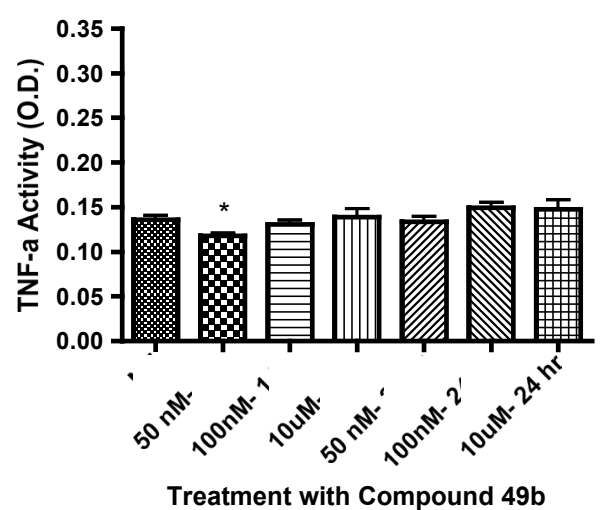

REC HG

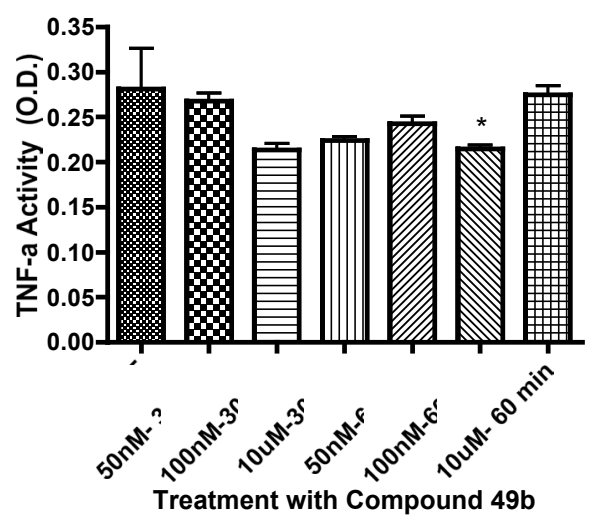

MÜLLER HG

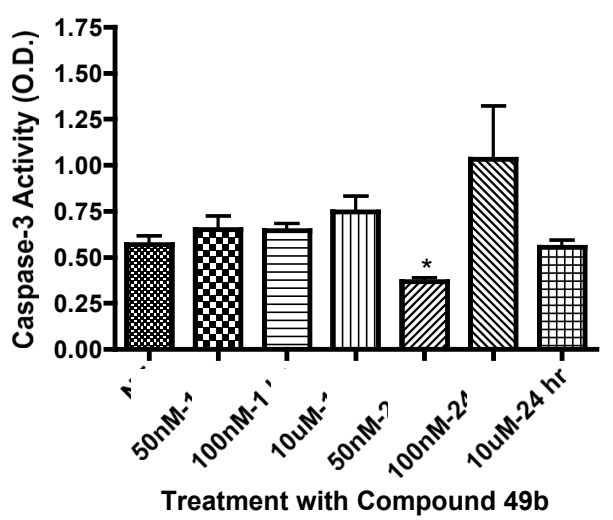

Figure 4-2. Bar Graph of Cleaved Caspase 3 and TNF- $\alpha$ Protein Levels on Retinal Endothelial Cells.

REC cultured in high glucose medium (top) and on Müller cells cultured in high glucose medium (bottom). Cells were treated with Compound $49 \mathrm{~b}$ for 30 -and 60 -minutes at the $50 \mathrm{nM}, 100 \mathrm{nM}$, and $10 \mathrm{uM}$ dosages. ${ }^{*} \mathrm{P}<0.05$ vs. NT, $\mathrm{N}=3$ independent dishes for each time point. 


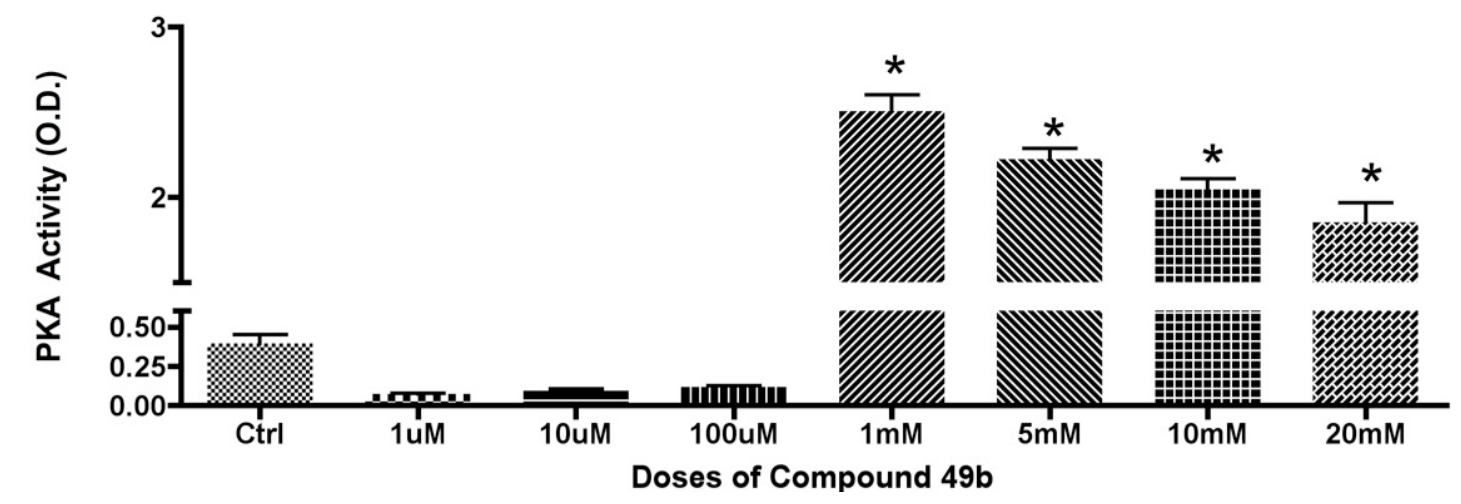

Figure 4-3. PKA ELISA Results.

Retinal lysates from diabetic rats treated with $1 \mathrm{uM}, 10 \mathrm{um}, 100 \mathrm{uM}, 1 \mathrm{mM}, 5 \mathrm{mM}, 10 \mathrm{mM}$, and $20 \mathrm{mM}$ dosages for 4 days. Rats receiving no treatment served as the controls. ${ }^{*} \mathrm{P}<0.05$ vs. $\mathrm{NT}, \mathrm{N}=4$. 
diabetic rats showed a significant reduction in b-wave amplitude, and oscillatory potential amplitudes (Figure 4-4). This is significant to note because the b-wave is the major waveform that is reduced in diabetes and the OP is used to diagnose diabetic retinopathy. Excitingly, in the delayed treatment groups, b-wave amplitudes at 8-months of diabetes with 2-months of treatment were much improved compared to the diabetes alone group (which included the same rats before treatment), suggesting that Compound 49b treatment maintained electrical activity in the retina of rats in both studies (Figure 4-5).

It has been previously demonstrated that diabetes decreases cell number and retinal thickness at 2-months (Barber et al 1998; Jiang et al 2010). In both the peripheral and central retina, the thickness of the retina was significantly reduced in diabetic rats receiving no treatment (Figure 4-6). The cell number in the ganglion cell layer (GCL) of the peripheral and central retinas were significantly reduced in diabetic rats as compared to control or diabetic $+49 \mathrm{~b}$ animals. Data suggest that treatment with Compound $49 \mathrm{~b}$ maintains the retinal thickness and cell number in spite of diabetes. In addition, Compound $49 \mathrm{~b}$ treatment was able to maintain retinal thickness and ganglion cell layer count similar to control rats in the delayed treatment studies.

Compound $49 \mathrm{~b}$ also significantly reduced the number of degenerate capillaries and pericyte ghost in comparison to diabetic only animals; however, values after Compound $49 \mathrm{~b}$ treatment were still significantly different than control values. The number of degenerate capillaries were also reduced to levels similar to control rats in the delayed treatment studies, while diabetic only rats showed significantly higher numbers (Figure 4-7).

Because caspase 3 levels were reduced after receptor stimulation with Compound $49 \mathrm{~b}$ in vitro, levels were analyzed in vivo. In both prevention and delayed treatment groups, untreated diabetic rats showed elevated levels of cleaved caspase 3 in comparison to control rats (Figure 4-8). Rats treated for 2-months with 1mM Compound 49b showed levels of cleaved caspase 3 similar to those of the control rats. Similarly, cleaved caspase 3 levels of rats treated with $1 \mathrm{mM}$ Compound $49 \mathrm{~b}$ were also similar to those of control rats in both groups after 8-months (prevention) and after 6-months (delayed), but were lower than untreated diabetic rats.

Because Akt activation is critical to the anti-apoptotic effects of insulin (Reiter et al 2006), protein levels of phosphorylated Akt were analyzed in retinal lysates of rats from each of the treatment groups. Akt phosphorylation levels were significantly higher in rats treated with Compound $49 \mathrm{~b}$ in comparison to non-treatment diabetic rats. Protein levels were significantly decreased in diabetic only rats when compared to control rats in both prevention and delayed treatment study groups (Figure 4-9). It has been reported that stimulation of the insulin receptor beta occurs primarily at the tyrosine 1150/1151 residues (Petruzelli et al 1984) in the rat; and that insulin receptors are present in the retina have high basal activity (Reiter et al 2006; Jiang et al 2010). We found that treatment with Compound $49 \mathrm{~b}$ maintained insulin receptor beta tyrosine phosphorylation. 


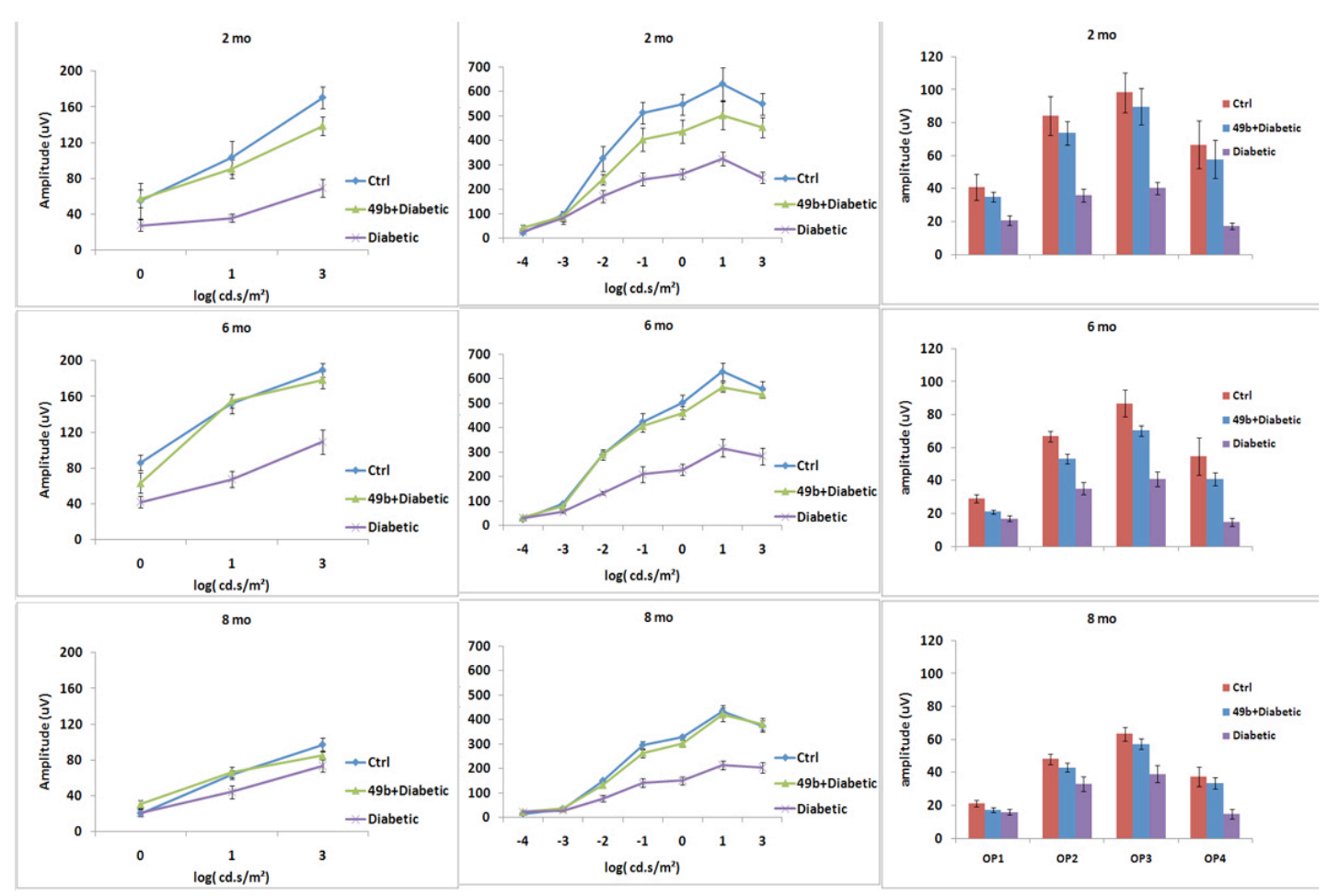

Figure 4-4. ERG Waveforms and Graphs after Compound 49b Treatment from the Prevention Group.

Panel A shows waveforms from one animal after 2-, 6-, and 8-months of treatment with Compound 49b. Line graphs in each panel represent mean \pm SD of the amplitude of rats of each of the three treatment groups. The left column is a-wave amplitude, middle column is b-wave amplitude, and the far right column is the oscillatory potential amplitude. 

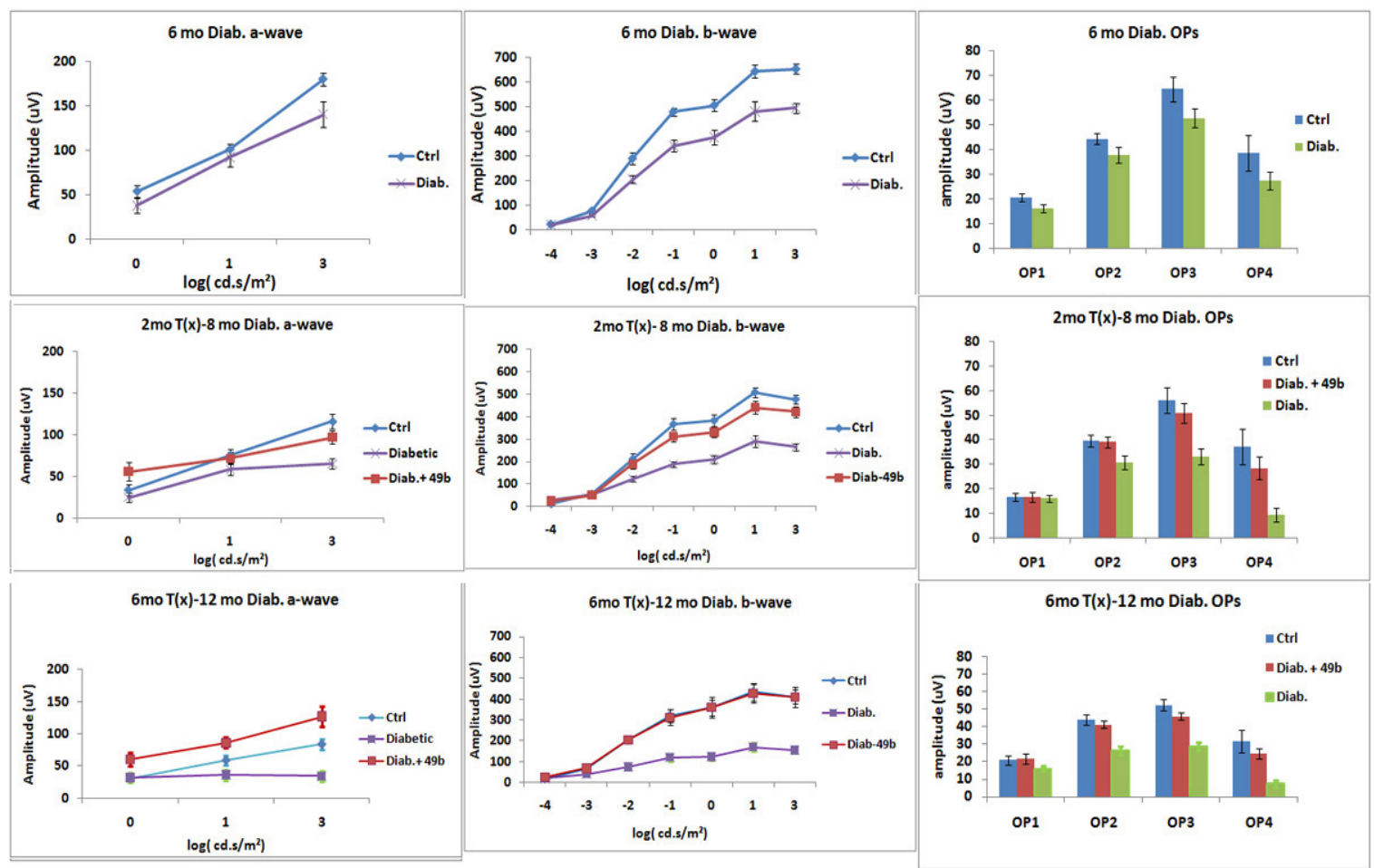

Figure 4-5. ERG Waveforms and Graphs after Compound 49b Treatment from the Delayed Treatment Group.

Top panel shows waveforms from animals after 6-months of diabetes and 2-and 6-months of treatment. Line graphs in each panel represent mean $\pm \mathrm{SD}$ of the amplitude of rats of each of the three treatment groups. The left column is a-wave amplitude, middle column is b-wave amplitude, and the far right column is the oscillatory potential amplitude. 


\section{Prevention}
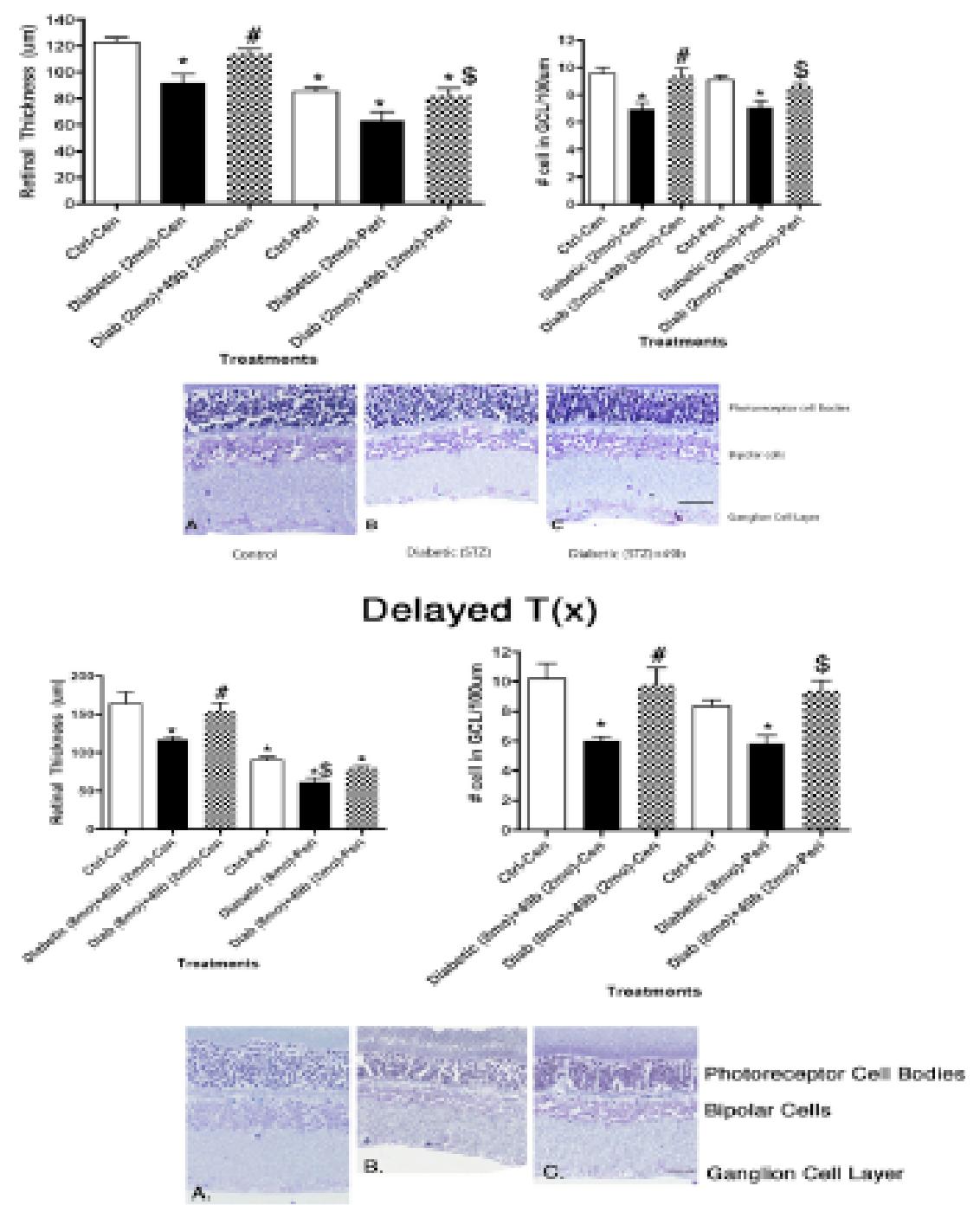

Figure 4-6. Results of Retinal Thickness and Ganglion Cell Layer Count.

Top panel is a representative bar graph of retinal thickness and ganglion cell layer count in peripheral and central retinas in prevention group. The bottom panel is a representative bar graph, which shows retinal thickness and ganglion cell layer count in peripheral and central retinas of animals from delayed treatment group. ${ }^{*} \mathrm{P}<0.05 \mathrm{vs}$. Ctrl, $\mathrm{N}=5$ independent subjects per group. ${ }^{\#} \mathrm{P}<0.05$ vs. Diabetic (central retina), $\mathrm{N}=6$ rats per group. ${ }^{\$} \mathrm{P}<0.05$ vs. Diabetic (peripheral retina), $\mathrm{N}=6$ rats per group.

Below each graph are corresponding images of retinal thickness and ganglion layers. 


\section{Prevention}
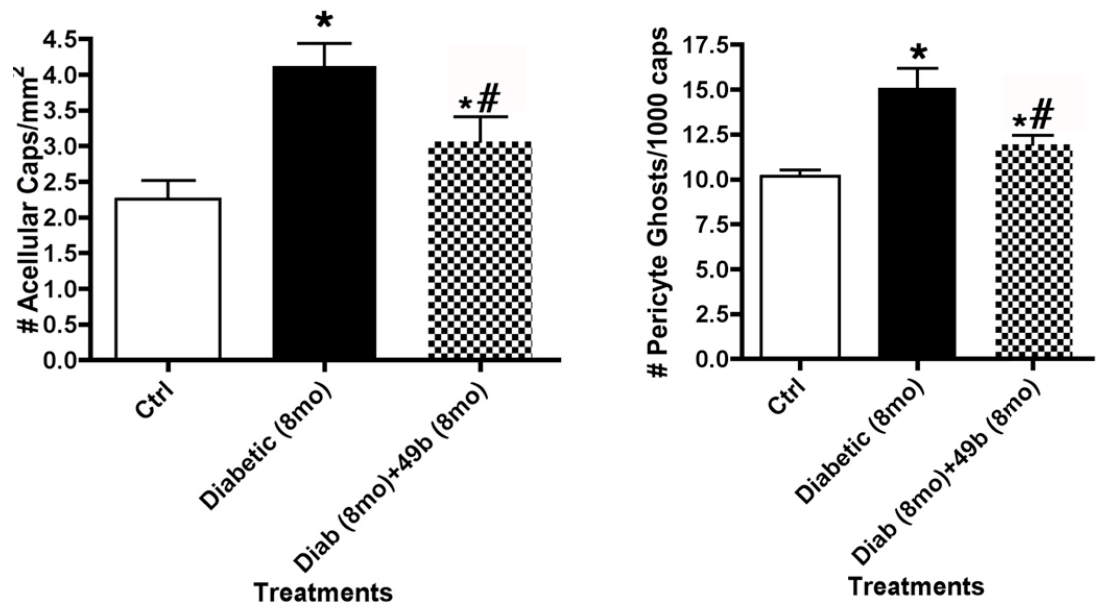

Delayed $\mathrm{T}(\mathbf{x})$
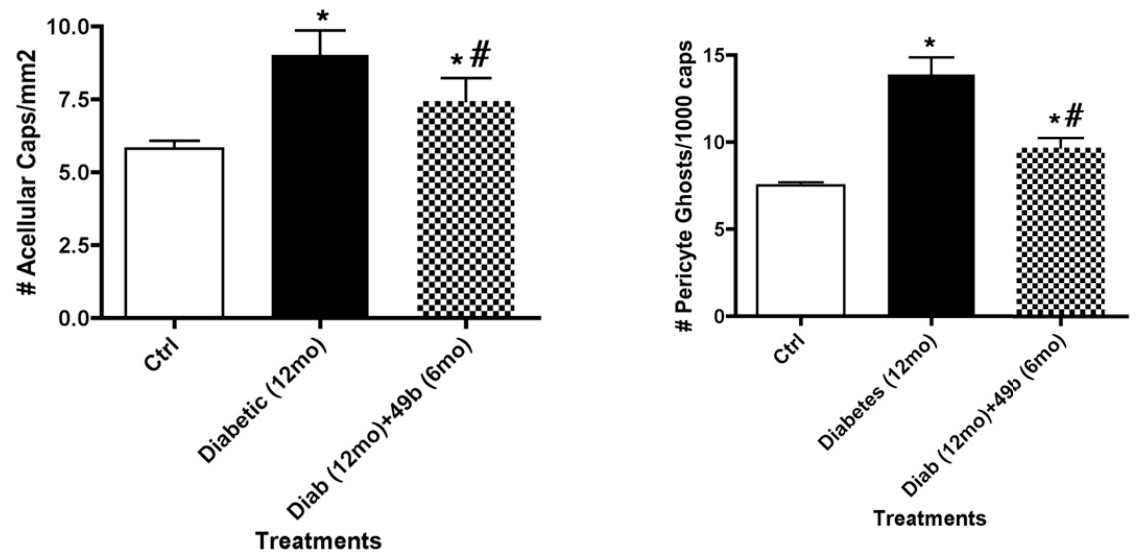

Figure 4-7. Bar Graph of Acellular Capillaries per Millimeter Squared of Retinal Tissue and Pericyte Ghost Counts of Control (Ctrl), Diabetic, and Treatment Rats (Diab+49b).

Top panel represents degenerate capillary counts in all treatment groups and pericyte ghost counts from prevention group, while bottom panel is representative of delayed treatment group. Eye drop treatment reduced the number of degenerate capillaries and pericyte ghosts in treatment rats. ${ }^{*} \mathrm{P}<0.05$ vs. $\mathrm{Ctrl}, \mathrm{N}=6$ independent subjects per group. ${ }^{\#} \mathrm{P}<0.05$ vs. Diabetic, $\mathrm{N}=6$ rats per group. 


\section{Prevention}
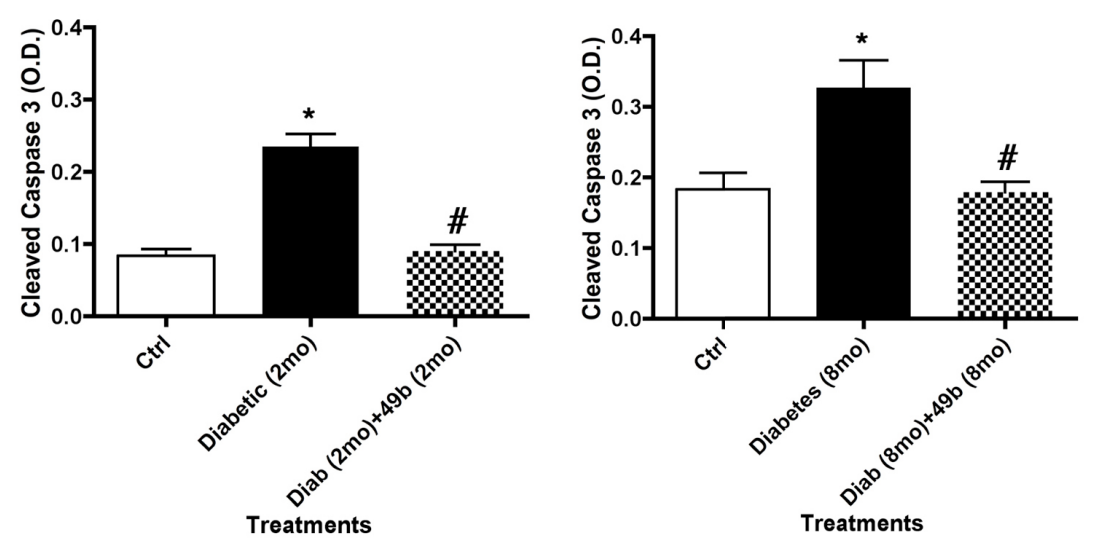

\section{Delayed $\mathrm{T}(\mathbf{x})$}
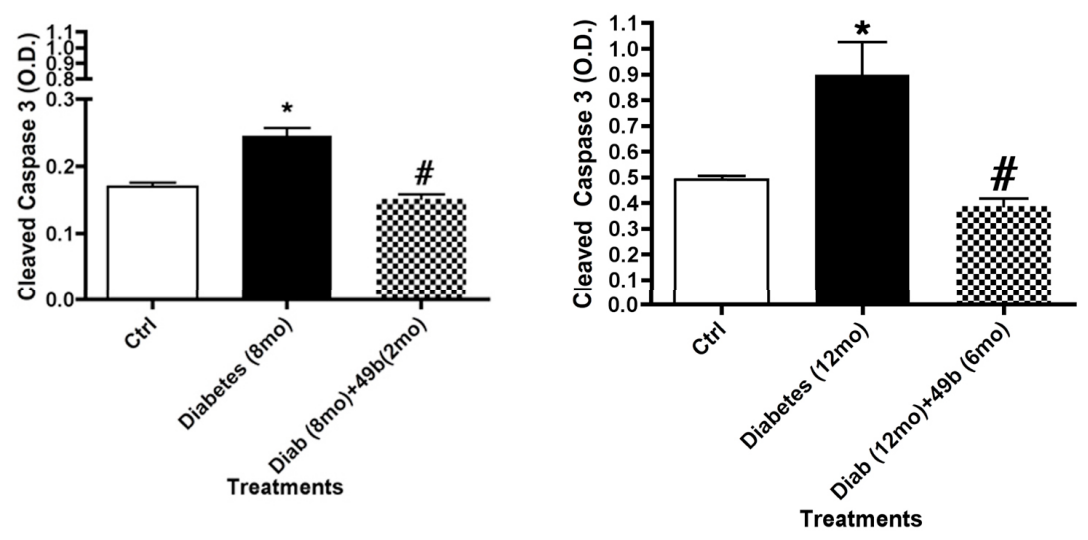

Figure 4-8. Results from Cleaved Caspase 3 ELISA on Retinal Lysates from Control (Ctrl), Diabetic, and Diabetic+Treatment Rats (Diab+49b).

Rats were treated daily $(\mathrm{Diab}+49 \mathrm{~b})$ for 2 -months and 6-, or 8-months. Top panel shows cleaved caspase 3 levels after treatment in prevention study and bottom panel shows cleaved caspase 3 levels after Compound 49b topical treatment in the delayed treatment study. ${ }^{*} \mathrm{P}<0.05$ vs. $\mathrm{Ctrl}, \mathrm{N}=6$ rats in each group at each time point. ${ }^{\#} \mathrm{P}<0.05$ vs. Diabetic, $\mathrm{N}=6$ rats per group. 


\section{Prevention}
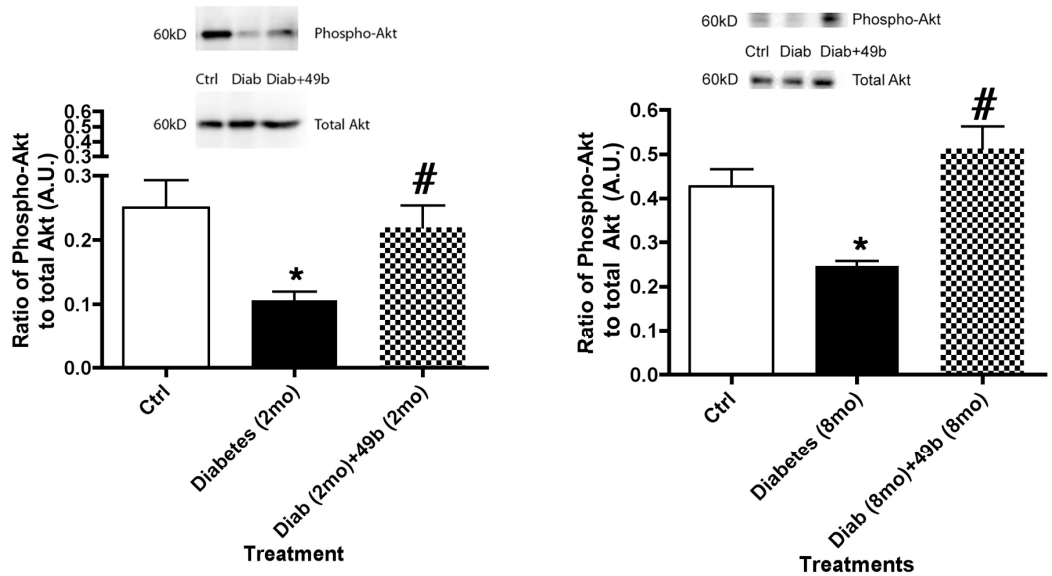

\section{Delayed T(x)}
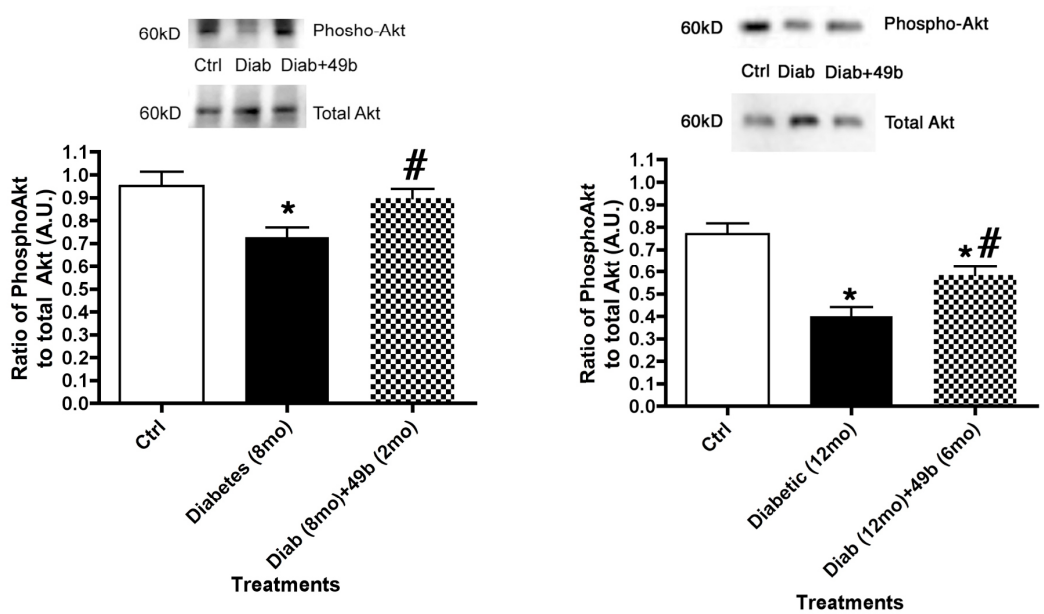

Figure 4-9. Bar Graph of the Ratio of Phosphorylated Akt and Total Akt Protein Levels.

Top panel represents ratio of phosphorylated Akt to total Akt after treatment in prevention study. Bottom panel represents the Akt ratio after treatment with Compound $49 \mathrm{~b}$ in delayed treatment study. ${ }^{*} \mathrm{P}<0.05$ vs. $\mathrm{Ctrl}, \mathrm{N}=6$ rats in each group at each time point. ${ }^{\#} \mathrm{P}<0.05$ vs. Diabetic, $\mathrm{N}=6$ rats per group. 
Insulin receptor beta tyrosine phosphorylation was elevated to levels similar to control animals after 2-months of treatment compared to non-treatment diabetic rats (Figure 4-10). Insulin receptor beta tyrosine phosphorylation was also maintained after 8 -months of diabetes in rats treated with Compound 49b. Delayed treatment with Compound 49b showed that insulin receptor beta tyrosine phosphorylation levels were significantly elevated in comparison to non-treatment diabetic rats after both 2- and 6 -months of treatment. These data suggest that Compound $49 \mathrm{~b}$ can prevent the reduction of insulin receptor beta phosphorylation in diabetic rat throughout both treatment studies.

Because a significant reduction in TNF- $\alpha$ levels was observed in vitro, levels were also assessed in vivo to insure that Compound $49 \mathrm{~b}$ was able to decrease inflammatory marker levels in diabetic rats. Prevention data show that after 2-months of treatment, protein levels of TNF- $\alpha$ were significantly elevated in non-treatment diabetic rats. Delayed treatment data showed that TNF- $\alpha$ protein levels were also significantly reduced post 2-months of treatment (Figure 4-11). TNF- $\alpha$ levels were significantly elevated in non-treatment diabetic rats after 8-months of Compound $49 \mathrm{~b}$ treatment and a similar elevation in TNF- $\alpha$ was seen after 12-months of diabetes in delayed treatment group.

TNF- $\alpha$ has been shown to interfere with normal insulin signaling by inhibiting tyrosine phosphorylation of IRS-1, though phosphorylation of the serine ${ }^{307}$ residue of IRS-1 (IRS-1Ser ${ }^{307}$ ) (Sykiotis \& Papavassiliou 2001). A significant increase in TNF- $\alpha$ levels was observed in non-treatment diabetic rats throughout both studies in comparison to control rats (Figure 4-11). After both 2-and 8-months of daily eye drop therapy, TNF- $\alpha$ levels were significantly reduced in comparison to non-treatment diabetic rats in the prevention study. Similarly, IRS-1Ser ${ }^{307}$ was reduced in Compound 49b-treated retinal lysates in the delayed treatment groups, as compared to non-treatment diabetic rats (Figure 4-12). Isoproterenol studies showed that diabetes-induced changes in heart structure were improved after treatment with $50 \mathrm{mM}$ topical application. We reasoned that isoproterenol entered the systemic circulation to elicit this effect. Compound $49 \mathrm{~b}$ treatment produced no changes in heart structure changes compared to diabetic rats (Figure 4-13).

\section{Discussion}

The goal of this study was to evaluate whether daily topical application of $1 \mathrm{mM}$ Compound $49 \mathrm{~b}$ could effectively reduce vascular, neuronal, apoptotic, and inflammatory markers of diabetic retinopathy, while preventing cardiovascular remodeling. In diabetes, modifications to the retina include basement membrane thickening, ganglion cell loss, capillary degeneration, inflammatory, and apoptotic marker level elevation (Wiley et al 2005). The hyperglycemic environment produced by diabetes has also been reported to alter sympathetic nerves (Burnstock 1990), which may affect adrenergic receptor signaling. We have previously demonstrated that loss of sympathetic innervation to the eye produces many of the same retinal features as diabetic retinopathy (Wiley et al 2005). Application of eye drops was able to prevent and delay retinal 


\section{Prevention}
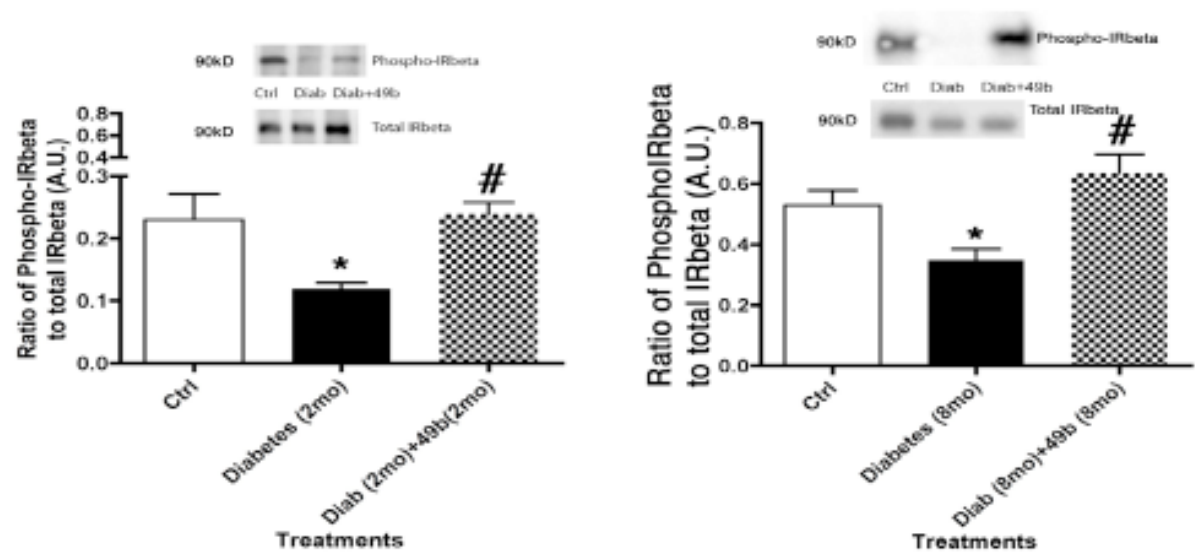

Delayed $\mathrm{T}(\mathbf{x})$
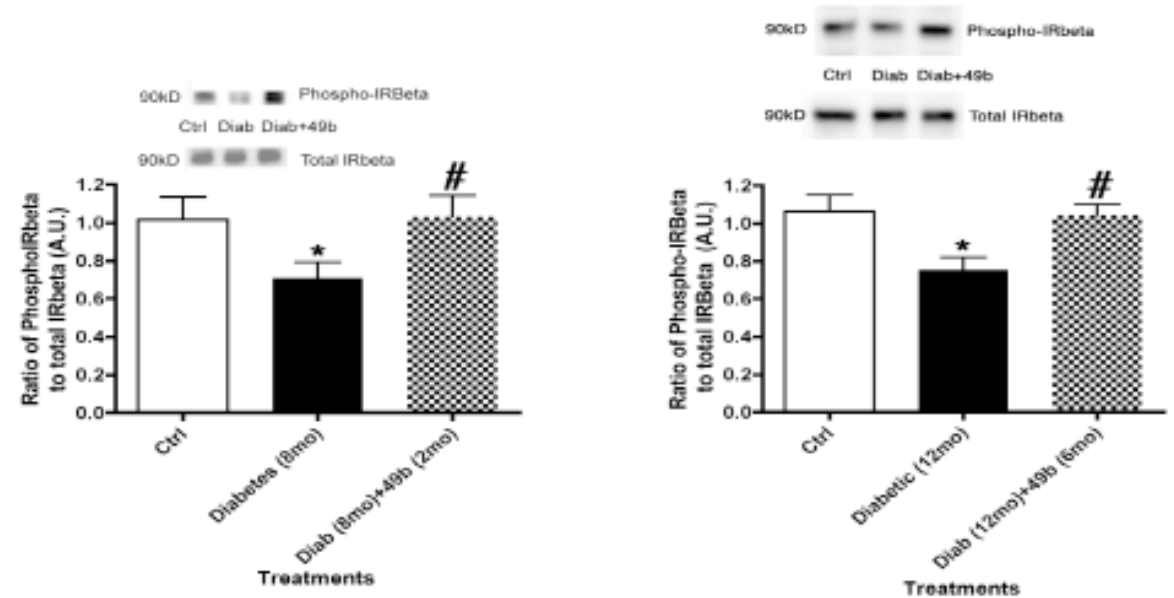

Figure 4-10. Bar Graph of the Ratio of Phosphorylated Insulin Receptor Beta (IRB) to Total Insulin Receptor Beta Protein Levels.

Top panel represents the ratio of phosphorylated IRB to total IRB after Compound $49 \mathrm{~b}$ daily treatment in prevention study rats. Bottom panel represents the ratio of phosphorylated IRB to total IRB after Compound 49b daily treatment in delayed treatment study. ${ }^{*} \mathrm{P}<0.05$ vs. $\mathrm{Ctrl}, \mathrm{N}=6$ rats per group. ${ }^{\#} \mathrm{P}<0.05$ vs. Diabetic, $\mathrm{N}=6$ rats per group. 


\section{Prevention}
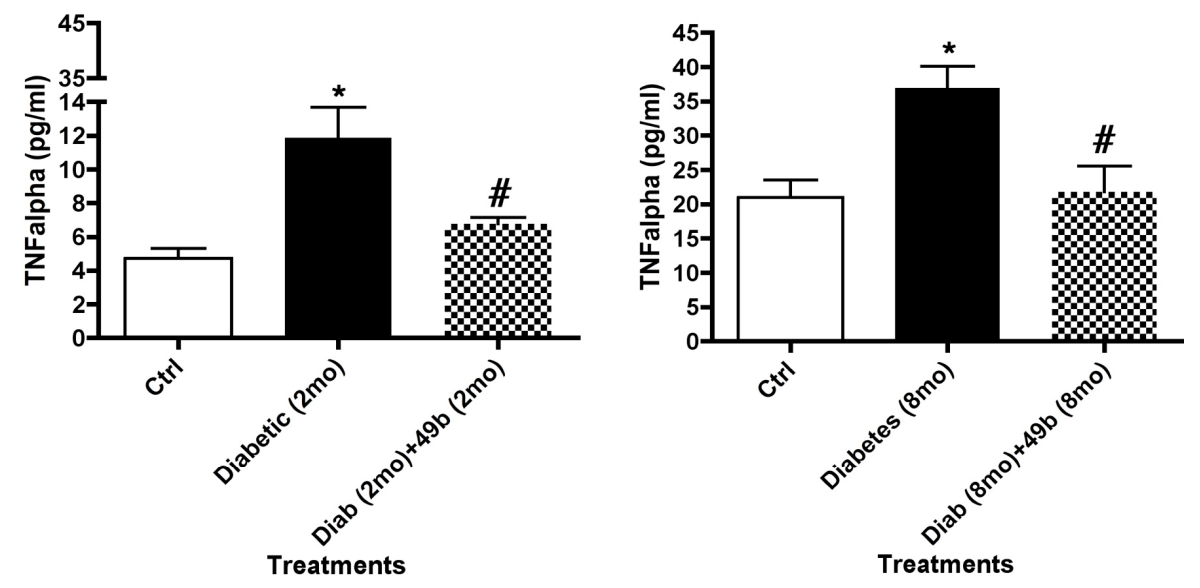

\section{Delayed $T(x)$}
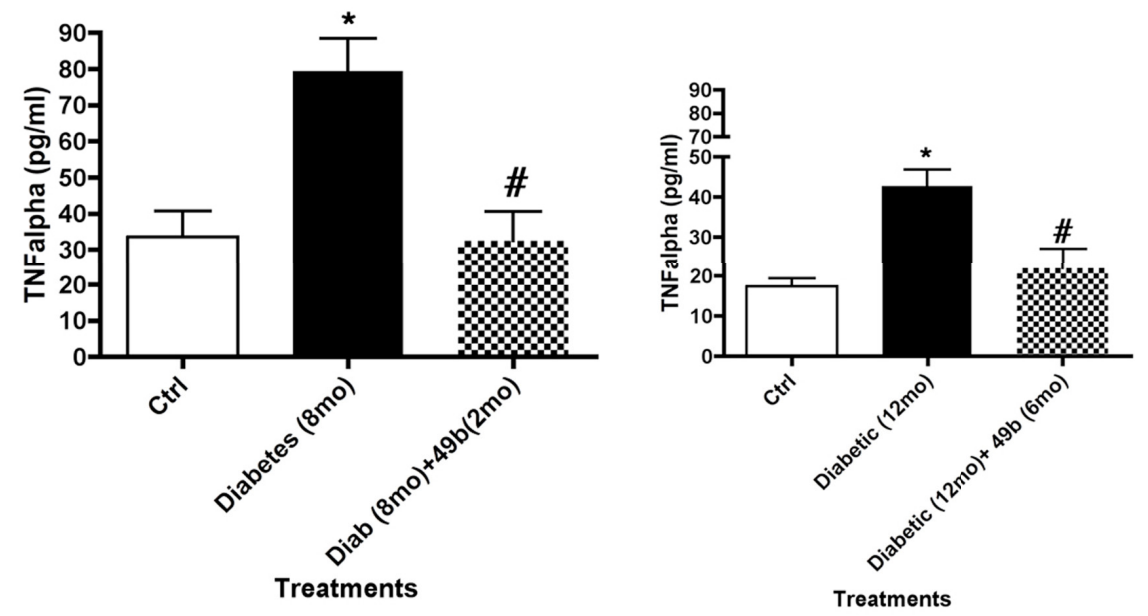

Figure 4-11. Results from TNF- $\alpha$ ELISA on Retinal Lysates from Control (Ctrl), Diabetic, and Diabetic+Treatment Rats (Diab+49b).

Panel A shows TNF- $\alpha$ protein levels after treatment in prevention study while panel B shows levels after treatment with Compound $49 \mathrm{~b}$ in delayed treatment study. ${ }^{*} \mathrm{P}<0.05$ vs. $\mathrm{Ctrl}, \mathrm{N}=6$ rat in each per group at each time point. ${ }^{\#} \mathrm{P}<0.05$ vs. Diabetic, $\mathrm{N}=6$ rats per group. 


\section{Prevention}

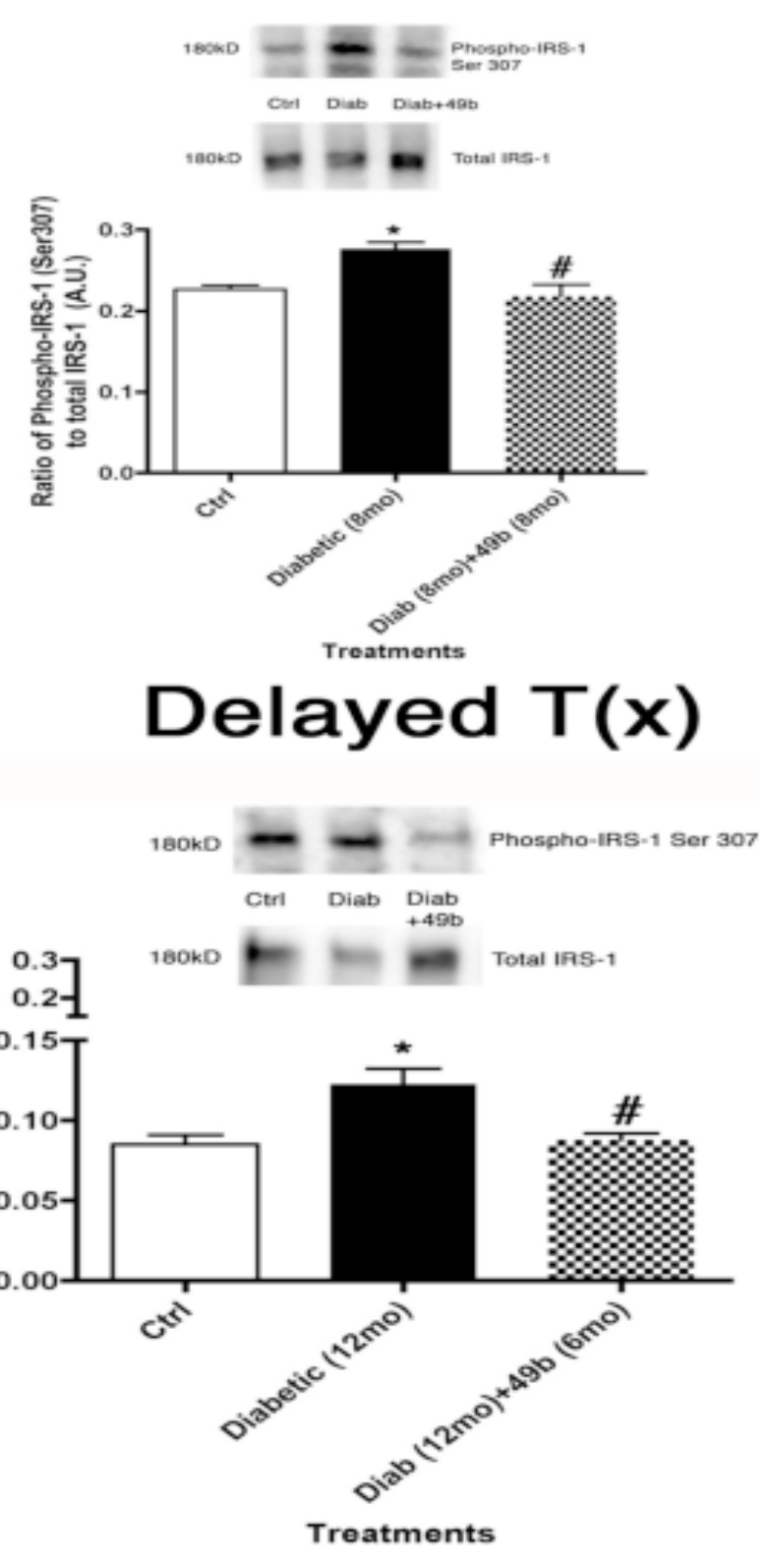

Figure 4-12. Bar Graph of the Ratio of Phosphorylated and Total Insulin Receptor Substrate-1 Protein Levels.

Top panel represents the ratio of phosphorylated IRS-1 to total IRS-1 after Compound $49 \mathrm{~b}$ daily treatment in prevention study. Bottom panel represents the ratio of phosphorylated IRS-1 to total IRS-1 in rats that received delayed treatment with Compound $49 \mathrm{~b}$. ${ }^{*} \mathrm{P}<0.05$ vs. $\mathrm{Ctrl}, \mathrm{N}=6$ rats per group. ${ }^{\#} \mathrm{P}<0.05$ vs. Diabetic, $\mathrm{N}=6$ rats per group. 

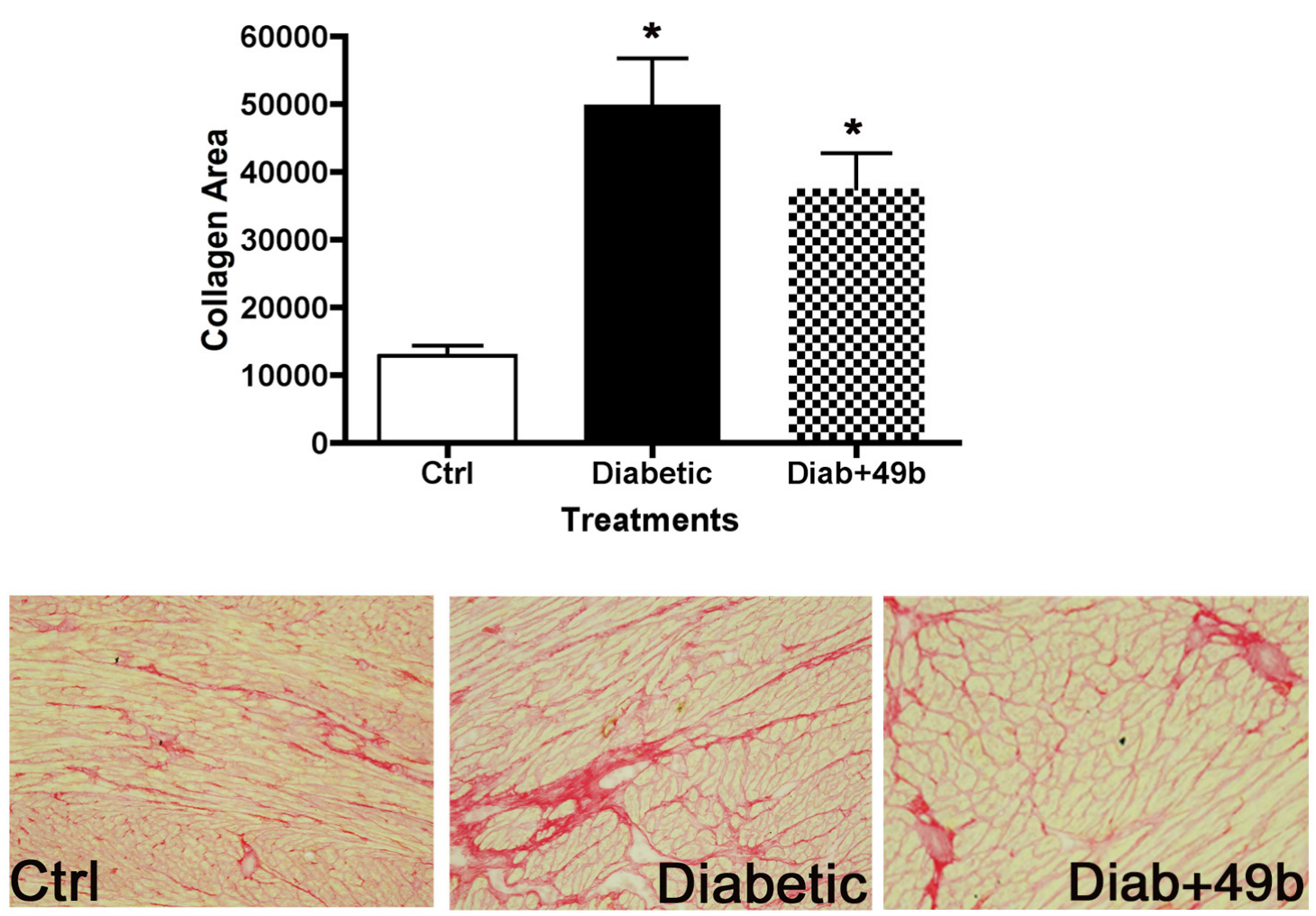

Figure 4-13. Heart Images from Control, Diabetic, and Diabetic+Compound 49b Rats.

Rats were treated daily with $1 \mathrm{mM}$ compound $49 \mathrm{~b}$ and at 8 -months heart images were obtained. Top figure represents heart images at 8-months. For bottom figures, left panel shows control (Ctrl) heart image, middle panel shows diabetic only, and right panel shows treated $(\mathrm{Diab}+49 \mathrm{~b})$ heart image. No change in heart morphology was observed in treatment sample. ${ }^{*} \mathrm{P}<0.05$ vs. $\mathrm{Ctrl}, \mathrm{N}=1$ rat per group. 
damage; however, the isoproterenol treatment affected the heart (Jiang et al 2010).

After screening various novel beta-adrenergic receptor agonists, we found that Compound 49b was able to reduce vascular and neuronal markers of diabetic retinopathy, without causing changes to the heart. In this study, we do find any changes in the left ventricle following topical Compound $49 \mathrm{~b}$ not treatment, which suggests that Compound $49 \mathrm{~b}$ does not repair diabetes-induced damage to the heart.

In spite of affecting the heart, isoproterenol was effective at reducing inflammatory and apoptotic marker levels, vascular and neuronal markers, and improving insulin receptor signaling in the diabetic retina (Jiang et al 2010) but lost this effect over time. Our data indicates that Compound $49 \mathrm{~b}$ was able to reduce these markers and sustained this reduction throughout the duration of both studies. While those diagnostic procedures used clinically to diagnose diabetic retinopathy, such as fluorescein angiography (Sinclair et al 1999), were not carried out, ERG analyses were used to evaluate retinal function. Monthly ERG analyses showed a significant reduction in the loss of $\mathrm{b}$ waveform amplitudes after treatment with Compound $49 \mathrm{~b}$ in both treatment groups, while a loss in function was observed in non-treatment rats. Supporting the localized effect of Compound 49b, intraocular pressure, body weight, blood pressure, or glucose levels were not influenced by eye drop therapy. A significant characteristic of diabetic retinopathy is formation of degenerate capillaries and pericyte ghosts (Kern \& Engerman 1996) and these two were used as markers of vascular damage in these studies. Compound $49 \mathrm{~b}$ was shown to reduce both markers in the delayed treatment and prevention study groups. Compound $49 \mathrm{~b}$ also improved neuronal measures in the retina, including preventing the loss of retinal thickness and cell number in the ganglion cell layer. These two neuronal markers were reduced in both the central and peripheral retinas, indicating that Compound $49 \mathrm{~b}$ was able to reduce vascular and neuronal changes associated with diabetes. In addition to maintaining normal vascular and neuronal histology in the retina, Compound $49 \mathrm{~b}$ eye drops also increased insulin receptor signaling and inhibited TNF- $\alpha$ levels and cleaved caspase 3 .

Basal insulin levels in the retina are reduced in the diabetes (Reiter et al 2006). Our data support this finding that insulin receptor phosphorylation is significant reduced in retinal lysates from untreated diabetic rats. Insulin has been reported to be a survival factor for R28 cells (a retinal ganglion cell line) (Xiaochua et al 2004), as well as retinal endothelial cells (Panjala \& Steinle 2011). The anti apoptotic actions of insulin occur through activation of Akt (Reiter et al 2006). Upstream regulation of insulin receptor signaling in the retina is less well understood. We have unpublished data to suggest that salmeterol, a selective beta-2-adrenergic receptor agonist, can significantly increase insulin receptor phosphorylation in retinal Müller cells, resulting in decreased apoptosis (data in submission). The present data with Compound 49b shows that beta-adrenergic receptor signaling can increase both insulin receptor and Akt phosphorylation, followed by reduction in cleavage of caspase 3 levels therefore inhibiting apoptosis. However, another aspect of Compound 49b's actions may be involved. Work in adipocytes and cardiac myocytes suggests that TNF- $\alpha$ can block the anti-apoptotic actions of insulin receptor through phosphorylation of serine ${ }^{307}$ on insulin receptor substrate-1. In this 
fashion, TNF- $\alpha$ is mediating a form of insulin resistance in these cell types. Our data suggest that diabetes also induces increased IRS-1 $\mathrm{Ser}^{307}$ phosphorylation in the retina, likely through the noted increased TNF- $\alpha$ levels in the diabetic retina. Both of these actions are reduced following topical Compound $49 \mathrm{~b}$ treatment. Taken together, these data suggest that Compound $49 \mathrm{~b}$ may prevent a form of retinal insulin resistance through decreased TNF- $\alpha$ levels, allowing the insulin receptor phosphorylation to be transduced to Akt and preventing apoptosis.

In conclusion, these results show that Compound $49 \mathrm{~b}$ is able to prevent and delay the progression of retinal damage in diabetic rat retina. In response to Compound $49 \mathrm{~b}$ treatment, TNF- $\alpha$ and cleaved caspase 3 levels were decreased. The reduction in TNF- $\alpha$ levels, likely prevented phosphorylation of IRS-1 $\mathrm{Ser}^{307}$, allowing the insulin signal to be transduced to prevent apoptosis. In this manner, Compound $49 \mathrm{~b}$ may be preventing a form of insulin resistance in the retina, through maintenance of insulin receptor actions, despite hyperglycemia. These results indicate that topical eye drop application of Compound $49 \mathrm{~b}$ may possibly serve as a novel therapeutic for diabetic retinopathy. 


\section{CHAPTER 5. SUMMARY AND CONCUSIONS}

\section{Correlations: Clinical and Non-Clinical Findings of Diabetic Retinopathy}

Diabetic retinopathy can be characterized by lesions on the fundus, which characterize the disease. These lesions include microaneurysms, hemorrhage spots, macular edema, and hard exudate formation (Viswanath \& McGavin 2003). While these lesions are non-specific to diabetes and the exact pathogenesis is unclear, these finding have been linked to pericyte degeneration or loss, a hallmark of diabetic retinopathy (Viswanath \& McGavin 2003). Compound 49b was shown to reduce pericyte loss in rats, linking our findings to published clinical findings of diabetic retinopathy. It is necessary to note that microaneurysm count can be used as an indicator of progression of diabetic retinopathy, but microanuerysm count was not evaluated in the studies presented here. Optical coherence tomography (OCT) images were however obtained from rats in all treatment groups (data not shown), showing that Compound 49b treatment appeared to reduce the loss of retinal thickness in rats. OCT has been widely accepted as a quantitative measurement of retinal thickness (Sanchez-Tocino et al 2002), which is decreased in diabetic retinopathy.

\section{The Novel Compound 49b}

In this study, we investigated the effectiveness of a novel beta-adrenergic receptor agonist, Compound 49b, in the treatment of diabetic retinopathy. Our in vitro and in vivo data suggests that topical treatment with Compound 49b in type 1 diabetic rats inhibits the hallmarks of diabetic retinopathy more effectively than a comparable non-selective beta-adrenergic receptor agonist, isoproterenol. We demonstrate that Compound 49b was able to significantly reduce markers of inflammation and apoptosis in vitro and in vivo in streptozotocin-induced diabetic rats with limited systemic exposure.

\section{Effects of Diabetes on Beta-Adrenergic Receptor Signaling}

Beta-adrenergic receptors are located in the heart, the lungs, kidney, retina and almost every other organ. In the heart, the presence of various beta-adrenergic receptor subtypes makes administration of beta-adrenergic receptor agonists critical. For example, it has been shown that the use of a non-selective beta-adrenergic receptor agonist, isoproterenol increases heart rate and contractility (Whalen \& Lewis 1999) when used for the treatment of the acute onset of asthma symptoms. Work with isoproterenol for cardiovascular disease has shown that isoproterenol enters the systemic circulation to induce left ventricular hypertrophy (Nagano et al 1992). Previous work in our lab with topical isoproterenol for diabetic retinopathy supported these findings, showing that the diabetes-induced damage to the heart was improved following isoproterenol therapy, indicating that isoproterenol likely entered the systemic circulation. We did find that 
isoproterenol was effective at restoring insulin signaling and neuronal and vascular changes associated with diabetic retinopathy in vitro at the $10 \mathrm{uM}$ and in vivo at the $50 \mathrm{mM}$ concentrations; however, isoproterenol lost its effectiveness over time and produced systemic effects, which limited its usefulness clinically. These findings led us to hypothesize that stimulation of beta-adrenergic receptors with a more selective beta-adrenergic receptor agonist may restore beta-adrenergic receptor signaling without producing systemic effects. It was therefore necessary to formulate a novel beta-adrenergic receptor agonist and investigate its ability to prevent the onset of retinal manifestations of diabetic retinopathy.

\section{Advantages of Compound 49b over Isoproterenol}

Topical treatment with Compound $49 \mathrm{~b}$ was shown to be more advantageous over topical treatment of isoproterenol in vivo. Compound $49 \mathrm{~b}$ is similar in structure to isoproterenol; with the addition of a N-substituent p-methoxyphenyl ring which helps the molecule lock into the beta-adrenergic receptor, leading to increased activity of Compound $49 \mathrm{~b}$ as compared to isoproterenol. We were able to measure the octanol-water partition coefficient ( $\log \mathrm{P}$ ) of isoproterenol and Compound 49b, which were 0.94 and 1.92, respectively. While isoproterenol was found to be effective at reducing markers of diabetic retinopathy in culture and in vivo, topical Compound $49 \mathrm{~b}$ treatment significantly reduced these same markers when administered at a lower concentration, $50 \mathrm{nM}$ and $1 \mathrm{mM}$ vs. $10 \mathrm{uM}$ and $50 \mathrm{mM}$ for isoproterenol. Also, Compound $49 \mathrm{~b}$ did not appear to alter diabetes-induced damage to the heart, suggesting that topical Compound $49 \mathrm{~b}$ did not reach the systemic circulation. Finally, Compound $49 \mathrm{~b}$ treatment was observed to prevent apoptosis and increase inflammatory mediators throughout the 12-month duration of these studies without losing efficacy.

\section{Specific Findings of Compound 49b}

In addition to limited systemic exposure, Compound $49 \mathrm{~b}$ was also able to reduce neuronal and vascular markers of diabetic retinopathy. It has been reported that retinal thickness and the number of cells in the ganglion cell layer is reduced in STZ rats (Barber et al 1998). While the exact pathophysiology of the disease is unknown, these results are beneficial and may add insight on the pathology of the disease. In diabetic retinopathy, the blood supply to the layers of the retina is damaged and occluded, leading to hypoxia and cell damage and loss. We see that with Compound $49 \mathrm{~b}$ treatment that cell loss in the retina was reduced and retinal thickness were increased. Clinical studies of diabetic retinopathy have primarily focused on identifying the source of vascular lesions to date. These combinations of vascular changes, unique to diabetic retinopathy, lead to decreased perfusion in the retina. Vascular integrity is essential in to maintain to ensure proper delivery of nutrients and oxygen to retina. In our present study two markers of vascular damage, pericyte loss and degenerate capillary formation were reduced after treatment with $1 \mathrm{mM}$ compound $49 \mathrm{~b}$. These findings infer that treatment not only reduced loss of neuronal tissue, but also prevented the occurrence of vascular problems associated 
with the disease. If we look into signaling molecules involved in the retina at the cellular level, we see other pathways that are influenced after Compound $49 \mathrm{~b}$ treatment. For example, as with isoproterenol studies insulin signaling, which is down regulated in diabetes, was increased significantly. While insulin signaling and its involvement in diabetic retinopathy has received very little investigation, it has been shown that insulin signaling is reduced and that apoptosis of retinal cells are up-regulated in diabetes (Chen et al 2005). Analyses of the key players in insulin signaling, in addition to apoptotic and inflammatory markers, were evaluated and showed an increase in insulin signaling, concurrent with a decrease in inflammation and apoptotic proteins. Findings from the Compound $49 \mathrm{~b}$ studies indicate that Compound $49 \mathrm{~b}$ is more effective that isoproterenol, without side effects. Future studies must be done to verify limited systemic toxicity.

\section{Potential Mechanisms of Action for Compound 49b}

Müller cells have been identified as a key player in the pathogenesis of diabetic retinopathy (Puro 2002). Müller cells have been shown to secrete inflammatory cytokines, such as TNF- $\alpha$ and IL-1B, upon activation (Pannicke et al 2005). It is worthy to note that inflammation is now recognized as a component of diabetic retinopathy (Joussen et al 2009) and may lead to the progression of microvascular and glial changes associated with the disease. In diabetes, insulin signaling is down regulated (Reiter et al 2006). It has also been shown that the insulin receptor is present in the retina (Chen et al 2005) and that insulin receptor signaling possesses anti-apoptotic properties, resulting from activation of Akt (Geraldes et al 2009). Work in our lab has demonstrated that TNF- $\alpha$ levels were significantly reduced after Compound $49 \mathrm{~b}$ treatment compared to untreated diabetic retinal lysates.

We also observed an increase in phosphorylation of Akt, likely leading to the observed decrease in the cleavage of caspase 3. Literature suggests that TNF- $\alpha$ can influence insulin receptor signal signaling (Sykiotis \& Papavassiliou 2001), leading to increased apoptosis. TNF- $\alpha$ alters insulin receptor actions through phosphorylation of $\mathrm{Ser}^{307}$ phosphorylation on IRS-1, leading to inhibition of insulin receptor action (Luca \& Olefsky 2008). Tyrosine phosphorylation of IRS-1 can lead to an increase in Akt phosphorylation and a decrease in the cleavage of caspase 3, resulting in decreased cell death (Walker \& Steinle 2007). Because a reduction in TNF- $\alpha$ protein levels were observed along with a subsequent increase in Akt phosphorylation and decrease in caspase 3, we hypothesize that Compound 49b may decrease cell death in diabetic retinopathy through reduced IRS-1 Ser ${ }^{307}$ phosphorylation, allowing for the restoration of insulin receptor signaling. Future studies are ongoing to test this hypothesis.

In retinal endothelial cells (REC), our data suggests that there is a separate mechanism by which Compound $49 \mathrm{~b}$ may regulate apoptosis. REC secrete insulin-like growth factor binding protein-3 (IGFBP-3). The physiological action of IGFBP-3 is to regulate circulating insulin-like growth factor-1 (IGF-1) levels. However, recently IGF-1-independent actions of IGFBP-3 have been reported (Yamada \& Lee 2009). IGFBP-3 has been observed in the retina in the oxygen-induced retinopathy model, with 
increased IGFBP-3 leading to a reduction in apoptosis of neovascular tufts (Lofqvist et al 2007). Data in our lab has shown that IGFBP-3 levels are reduced in high glucose and in the diabetic rat retina. With Compound $49 \mathrm{~b}$ treatment, we observed an increase in IGFBP-3 levels in REC, along with a decrease in apoptotic markers Fas, FasL, Bax, and cytochrome-C. To provide a potential mechanism, it is worthy to note that PKA levels were increased after Compound 49b treatment in REC cultured in high glucose.

Subsequently, work carried out by other members in our lab has shown that after PKA inhibition using siRNA, Compound 49b-induced increases in IGFBP.-3 levels were reduced. Similarly, Compound 49b was unable to inhibit REC apoptosis when combined with IGFBP-3 siRNA. We hypothesize that beta-adrenergic receptor stimulation with Compound $49 \mathrm{~b}$ reduces REC apoptosis by up-regulating PKA activity and increased IGFBP-3 levels. Together this data suggests that Compound $49 \mathrm{~b}$ regulates REC apoptosis via an IGF-1 independent, PKA-dependent pathway. Ongoing studies are currently testing this hypothesis.

\section{Limitations to the Compound 49b Study}

In our studies, our results are very supportive of our overall hypothesis; however, there are always limitations. While caspase 3 was used a marker of apoptosis, it is clear that a reduction in one protein does not directly correlate to reduced apoptosis. To further our studies on apoptosis, we can investigate other markers of apoptosis and use a Cell Death Detection ELISA to detect oligonucleosome formation. It is also worth noting that delayed treatment data as done does not demonstrate that Compound 49b directly reverses diabetes induced changes. Inclusion of data representing rats with no treatment at 8-and 12-months of diabetes without treatment may be able to begin to address whether Compound $49 \mathrm{~b}$ can truly reverse diabetic-like changes in the retina. The use of additional controls, such as rats receiving saline only injections and lower concentrations of Compound 49b, in our in vivo studies would allow the ability to make more exact and irrefutable conclusions about the effectiveness of Compound 49b. The omissions of such controls are present, but do not disqualify literature-supported findings from the data presented.

\section{Future Studies}

In light of the data presented here, there are still other studies that must be carried out to offer more insight for translation of Compound $49 \mathrm{~b}$ to patient care. Further optimization and carrying out antagonist studies with specific beta-1, 2 adrenergic receptor agonists can show which receptor subtype the compound utilizes to modulate it effects. In addition, pharmacokinetic studies will offer support for the antagonist study and offer insight on the systemic exposure of the drug via plasma sample analyses. Radio ligand binding studies may potentially show that the drug actually binds the one or more of the beta-adrenergic receptor subtypes. For our in vivo studies, inclusion of monitoring retinal changes in diabetic rats receiving no treatment for the duration of 12 months may be beneficial. If promising data is obtained from the above experiments, efficacy and 
toxicity studies may be appropriate to test the drug's ability to efficiently work in vivo and to ensure that the drug does not cause adverse side effects. 


\section{LIST OF REFERENCES}

Abu El Asrar, E.M., Missotten, L., \& Geboes, K. (2007). Expression of hypoxia-inducible factor-1 alpha and the protein products of its target genes in diabetic fibrovascular epiretinal membranes. Br J Ophthalmol, 91(6), 822-826.

Aiello, L.P., Gardner, T.W., King, G.L., Blankenship, G., Cavallerano, J.D., Ferris, F.L., et al. (1998). Diabetic retinopathy. Diab Care, 21(1), 143-156.

Avogaro, A. (2003). Diabetes and multimetabolic syndrome. Ital Heart J, 4(7), 13S-21S.

Barber, A.J., Lieth, E., Khin, S.A., Antonetti, D.A., Buchanan, A.G., \& Gardner, T.W. (1998). Neural apoptosis in the retina during experimental and human diabetes. Early onset and effect of insulin. J Clin Invest, 102(4), 783-791.

Benarroch, E.E., Sandroni, P., \& Low, P.A. (1993). The Valsalva maneuver. In P.A. Low (Ed.), Clinical Autonomic Disorders: Evaluation and Management. (pp.209-215). Boston, MA: Little \& Brown.

Berkman, J., \& Rifkin, H. (1973). Unilateral nodular diabetic glomerulosclerosis (Kimmelstiel-Wilson): report of a case. Metab, 22(5), 715-722.

Bortolato, A., Mobarec, J.C., Provasi, D., \& Filizola, M. (2009). Progress in elucidating the structural and dynamic character of $\mathrm{G}$ protein-coupled receptor oligomers for use in drug discovery. Curr Pharm Des, 15(35), 4017-4025.

Burnstock, G. (1990). Overview-purinergic mechanisms. Ann N Y Acad Sci, 603, 1-17.

Chen, H.S., Shan, Y.X., Yang, T.L., Lin, H.D., Chen, J.W., \& Lin, S.J. (2005). Insulin deficiency downregulated heat shock protein 60 and IGF-1 receptor signaling in diabetic myocardium. Diab, 54(1), 175-181.

Chen-Izu, Y., Xiao, R.P., Izu, L.T., Cheng, H., Kuschel, M., Spurgeon, H., et al. (2000). $\mathrm{G}(\mathrm{i})$-dependent localization of beta (2)-adrenergic receptor signaling to L-type $\mathrm{Ca}$ (2+) channels. Biophys J, 79(5), 2547-2556.

Chew, E.Y., Ferris, F.L., Csaky, K.G., Murphy, R.P., Agrón, E., Thompson, D.J., et al. (2003). The long-term effects of laser photocoagulation treatment in the patients with diabetic retinopathy: The early treatment diabetic retinopathy follow-up study. Ophthalmol, 110(9), 1683-1689.

Cusick, M., Chew, E.Y., Clemons, T.E., Klein, R., Klein, B.E., \& Hubbard, L.D. (2002). Effect of antioxidant and zinc supplements on development of diabetic retinopathy in the Age-Related Eye Disease Study (AREDS). Invest Ophthalmol Vis Sci, 43, E 1909. 
Daniel, T.O., Gibbs, V.C., Milfay, D.F., \& Williams, L.T. (1987). Agents that increase cAMP accumulation block endothelial c-sis induction by thrombin and transforming growth factor-beta. J Biol Chem, 262(25), 11893-11896.

Davis, M.D., Fisher, M.R., Gangnon, R.E., Barton, F., Aiello, L.M., Chew, E.Y., et al. (1998). Risk factors for high-risk proliferative diabetic retinopathy and severe visual loss: early treatment diabetic retinopathy study report \#18. Invest Ophthalmol Vis Sci, 39(2), 233-252.

Delair, E., Creuzet, C., Dupouy-Camet, J., \& Roisin, M.P. (2009). In vitro effect of TNF-alpha and IFN-gamma in retinal cell infection with Toxoplasma gondii. Invest Ophthalmol Vis Sci, 50(4), 1754-1760.

Ejaz, S., Chekarova, I., Ejaz, A., Sohail, A., \& Lim, C.W. (2008). Importance of pericytes and mechanisms of pericyte loss during diabetes retinopathy. Diab Obes Metab, 10(1), 53-63.

Ferrnyhough, P., \& Schmidt, R.E. (2002). Neurofilaments in diabetic neuropathy. Int Rev Neurobiol, 50, 115-144.

Flynn, M.D., \& Tooke, J.E. (1992). Aetiology of diabetic foot ulceration: a role for the microcirculation? Diab Med, 9(4), 320-329.

Frank, R.N. (2004). Diabetic retinopathy. N Engl J Med, 350(1), 48-58.

Fraser-Bell, S., Kaines, A., \& Hykin, P.G. (2008). Update on treatments for diabetic macular edema. Curr Opin Ophthalmol, 19(3), 185-189.

Frishman, W.H. (2003). Cardiology patient page: beta-adrenergic blockers. Circ, 107(18), 117-119.

Furukawa, H. (1987). Autonomic innervation of preretinal blood vessels of the rabbit. Invest Ophthalmol Vis Sci, 28(11), 1752-1760.

Gao, Z., Young, R.A., Trucco, M.M., Greene, S.R., Hewlett, E.L., Matschinsky, F.M., et al. (2002). Protein kinase A translocation and insulin secretion in pancreatic beta-cells: studies with adenylate cyclase toxin from Bordetella pertussis. Biochem J, 368(2), 397-404.

Geraldes, P., Hiraoka-Yamamoto, J., Matsumoto, M., Clermont, A., Legites, M., Marette, A., et al. (2009). Activation of PKC-delta and SHP-1 by hyperglycemia causes vascular cell apoptosis and diabetic retinopathy. Nat Med, 15(11), 1298-1306.

Ghanouni, P., Steenhius, J.J., Farrens, D.L., \& Kobilka, B.K. (2001). Agonist-induced conformational changes in the G-protein-coupling domain of the beta-2 adrenergic receptor. Proc Natl Acad Sci U S A, 98(11), 5997-6002. 
Giubergia, V., Zelazko, M., Roy, A., Gravina, L.P., Pena, H.G., \& Chertkoff, L. (2009). Beta-2 AR polymorphism (homozygous arginine 16) associated with higher IgE in children with asthma. Asth and Immunol, 102, (4), 308-313.

Grubb, B.P., Karas, B., Kosinski, D., \& Boehm, K. (1999). Preliminary observations on the use of mododrine hydrochloride in the treatment of refractory neurocardiogenic syncope. J Inery Card Electrophysiol, 3(2), 139-143.

Heather, L.C., Catchpole, A.F., Stuckey, D.J., Cole, M.A., Carr, C.A., \& Clarke, K. (2009). Isoproterenol induces in vivo functional and metabolic abnormalities: similar to those found in the infarcted rat heart. J Physiol Pharmacol, 60(3), 31-39.

Jandrastis, K., Lukscg, A., Söregi, G., Dorner, G.T., Polak, K., \& Schmetterer, L. (2002). Effect of noradrenaline on retinal blood flow in healthy subjects. Ophthalmol, 109(2), 291-295.

Jiang, Y., Walker, R.J., Kern, T.S., \& Steinle, J.J. (2010). Application of isoproterenol inhibits diabetic-like changes in the rat retina. Exp Eye Res, 91(2), 171-179.

Joost, P., \& Mehtner, A. (2002). Phylogenetic analysis of 277 human G-protein-coupled receptors as a tool for the prediction of orphan receptor ligands. Genome Biol, 3(11), RESEARCH0063.

Joussen, A.M., Doehmen, S., Le, M.L., Koizumi, K., Radetzky, S., Krohne, T.U., et al. (2009). TNF-alpha mediated apoptosis plays an important role in the development of early diabetic retinopathy and long-term histopathological alterations. Mol Vis, 25(15), 1418-1428.

Kabir, S.M., Mukherjee, S., Rajaratnam, V., Smith, M.G., \& Das, S.K. (2009). Desensitization of beta-adrenergic receptors in lung injury induced by 2-chloroethyl ethyl sulfide, a mustard analog. J Biochem Mol Toxicol, 23(1), $59-70$.

Kamangar, F., Cheng, C., Abnet, C.C., \& Rabkin, C.S. (2006). Interleukin-1B polymorphisms and gastric cancer risk-a meta-analysis. Cancer Epidemiol Biomarkers Prev, 15(10), 1920-1928.

Kern, T.S., \& Engerman, R.L. (1994). Comparison of retinal lesions in alloxan-diabetic rats and galactose-fed rats. Cur Eye Res, 13(12), 863-867.

Kern, T.S., \& Engerman, R.L. (1995). Retinopathy in galactosemic dogs continues to progress after cessation of galactosemia. Arch Ophthalmol, 113(3), 355-358.

Kern, T.S., \& Engerman, R.L. (1996). Capillary lesions develop in retina rather than cerebral cortex in diabetes and experimental galactosemia. Arch Ophthalmol, 114(3), 306-310. 
Kim, J.M., Lee, E.K., Kim, D.H., Yu, B.P., \& Chung, H.Y. (2010). Kaempferol modulates pro-inflammatory NF-kappaB activation by suppressing advanced glycation endproducts-induced NADPH oxidase. Age, 32(2), 197-208.

Klein, R., Klein, B.E., \& Moss, S.E. (1995). The Wisconsin epidemiologic study of diabetic retinopathy, XVI: the relationship of C-peptide to the incidence and progression of diabetic retinopathy. Diab, 44(7), 796-801.

Kowluru, R.A., \& Odenbach, S. (2004). Role of interleukin-1 beta in the pathogenesis of diabetic retinopathy. Br J Ophthalmol, 88(10), 1343-1347.

Laties, A.M., \& Jacobowitz, D. (1966). A comparative study of the autonomic innervation of the eye in monkey, cat, and rabbit. Anat Rec, 156(4), 383-395.

Lavrik, I., Golks, A., \& Krammer, P.H. (2005). Death receptor signaling. J Cell Sci, 118, 265-267.

Locksley, R.M., Kileen, N., \& Lenardo, M.J. (2001). The TNF and TNF-receptor superfamilies: integrating mammalian biology. Cell, 104(4), 487-501.

Lofqvist, C., Chen, J., Connor, K.M., Smith, A.C., Aderman, C.M., Liu, N., et al. (2007). IGFBP-3 supresses retinopathy through suppression of oxygen-induced vessel loss and promotion of vascular regrowth. Proc Natl Acad Sci U S A, 104(25), 10589-10592.

Luca, C., \& Olefsky, J.M. (2008). Inflammation and insulin resistance. FEBS letters, 582(1), 97-105.

Maritim, A., Dene, B.A., Sanders, R.A., \& Watkins, J.B. (2002). Effects of beta-carotene on oxidative stress in normal and diabetic rats. J Biochem Mol Toxicol, 16(4), 203-208.

Mohr, S., Xia, X., Tang, J., \& Kern, T.S. (2002). Caspase activation in the retinas of diabetic and galactosemic mice and diabetic patients. Diab, 51(4), 1172-1179.

Nagano, M., Higaki, J., Nakamura, F., Higashimori, K., Nagano, N., Mikami, H., et al. (1992). Role of cardiac angiotensin II in isoproterenol-induced left ventricular hypertrophy. Hyperten, 19, 708-712.

Panjala, S.R., \& Steinle, J.J. (2011). Insulin and $\beta$-adrenergic receptors inhibit retinal endothelial cell apoptosis through independent pathways. Neurochem Res, 36(4), 604-612.

Panjala, S.R., Thomas, S.A., \& Steinle, J.J. (2010). Effects of insulin-like growth factor-1 (IGF-1) receptor signaling on rates of apoptosis in retina of dopamine hydroxylase (Dbh- $I-$ ) knockout mice. Auton Neurosci, 152(1-2), 21-26. 
Pannicke, T., Uckermann, O., Iandiev, I., Biedermann, B., Wiedemann, P., \& Perlman, I. (2005). Altered membrane physiology in Müller glial cells after transient ischemia of the rat retina. Glia, 50(1), 1-11.

Pardianto, G. (2005). Understanding diabetic retinopathy. Mimbar Ilmiah Ofalmologi Indonesia, 2, 65-66.

Petruzelli, L., Herrera, R., \& Rosen, O.M. (1984). Insulin receptor is an insulin-dependent tyrosine protein kinase: copurification of insulin-binding activity and protein kinase activity to homogeneity from human placenta. Proc Natl Acad Sci U S A, 81(11), 3327-3331.

Puro, D.G. (2002). Diabetes-induced dysfunction of retinal Müller cells. Trans Am Ophthalmol Soc, 100, 339-352.

Reiter, C.E., Wu, X., Sandirasegarane, L., Nakamura, M., Gilbert, K.A., Singh, R.S., et al. (2006). Diabetes reduces basal retinal insulin receptor signaling: reversal with systemic and local insulin. Diab, 55(4), 1148-1156.

Sagrada, A., Fargeas, M.J., \& Bueno, L. (1987). Involvement of alpha-1 and alpha-2 adrenoreceptors in the postlaparotomy intestinal motor disturbances in the rat. Gut, 28(8), 955-959.

Said, G. (2007). Diabetic neuropathy-a review. Nat Clin Pract Neurol, 3(6), 331-340.

Salvesen, G.S. (2002). Caspases and apoptosis. Essays Biochem, 38, 9-19.

Sánchez-Tocino, H., Alvarez-Vidal, A., Maldonado, M.J., Moreno-Montañés, J., \& García-Layana, A. (2002). Retinal thickness study with optical coherence tomography in patients with diabetes. Invest Ophthalmol Vis Sci, 43(5), 1588-1594.

Schmitz, J.M., Graham, R.M., Sagalowsky, A., \& Pettinger, W.A. (1981). Renal alpha-1 and alpha-2 adrenergic receptors: biochemical and pharmacological correlations. J Pharmacol Exp Ther, 219(2), 400-406.

Sharma, S., \& Chandrarajan, K. (2004). Diabetic retinopathy: prevalence and prevention. Diab Microvas Comp Today, 1(2), 30-32.

Sinclair, S.H., Alaniz, R., \& Presti, P. (1999). Laser treatment of diabetic macular edema: comparison of ETDRS-level treatment with threshold-level treatment by using high-contrast discriminant central visual field testing. Semin Ophthalmol, 14(4), 214-222.

Steiner, D.F., \& Oyer, P.F. (1967). The biosynthesis of insulin and probable precursor of insulin by a human islet cell adenoma. Pro Natl Acad Sci U S A, 57(2), 473-480.

Steinle, J.J. (2007). Sympathetic neurotransmission modulates expression of inflammatory markers in the rat retina. Exp Eye Res, 84(1), 118-125. 
Steinle, J.J. (2009). Increased basement membrane thickness, pericyte ghosts, and loss of retinal thickness and cells in dopamine beta hydroxylase knockout mice. Exp Eye Res, 88(6), 1014-1019.

Steinle, J.J., Lindsay, N.L., \& Lashbrook, B.L. (2005). Cervical sympathectomy causes photoreceptor-specific cell death in the rat retina. Auton Neurosci, 120(1-2), 4651.

Steinle, J.J., \& Smith, P.G. (2002). Role of adrenergic receptors in vascular remodeling of the rat choroid. Br J Pharmacol, 136(5), 730-734.

Steinle, J.J., \& Smith, P.G. (2003). Sensory but not parasympathetic nerves are required for ocular vascular remodeling following chronic sympathectomy in rat. Auton Neurosci, 109(1-3), 32-41.

Sykiotis, G.P., \& Papavassiliou, A.G. (2001). Serine phosphorylation of insulin receptor substrate-1: a novel target for the reversal of insulin resistance. Mol Endocrinol, 15(11), 1864-1869.

Tak, P.P., \& Firestein, G.S. (2001). NF-kappaB: a key role in inflammatory diseases. J Clin Invest, 107, 7-11.

Tanaguchi, C.M., Emanualli, B., \& Kahn, C.R. (2006). Critical nodes in signaling pathways: insights into insulin action. Nat Rev Mol Cell Biol, 7(2), 85-96.

Udelson J.E., Cannon, R.O., Bacharach, S.L., Rumble, T.F., \& Bonow, R.O. (1989). Beta-adrenergic stimulation with isoproterenol enhances left ventricular diastolic performance in hypertrophic cardiomyopathy despite potentiation of myocardial ischemia: comparison to rapid atrial pacing. Circ, 79(2), 371-382.

van den Oever, I.A.M., Raterman, H.G., Nurmohamed, M.T., \& Simsek, S. (2010). Endothelial dysfunction, inflammation, and apoptosis in diabetes mellitus. Mediators Inflamm, 2010 (792393), 1-12.

Vassilatis, D.K., Hohnmann, J.G., Zeng, H., Li, F., Ranchalis, J.E., Mortrud, M.T., Brown, A., et al. (2003). The G protein-coupled receptor repertoires of human and mouse. Proc Natl Acad Sci U S A, 100(8), 4903-4908.

Viswanath, K., \& McGavin, D.D. (2003). Diabetic retinopathy: clinical findings and management. Comm Eye Health, 16(46), 21-24.

Walker, R.J., \& Steinle, J.J. (2007). Role of beta-adrenergic receptors in inflammatory marker expression in Müller cells. Invest Ophthalmol Vis Sci, 48(11), 5276-5281.

Wang, J., Williams, D.E., Narayan, K.M., \& Geiss, L.S. (2006). Declining death rates from hyperglycemic crisis among adults with diabetes, U.S., 1985-2002. Diab Care, 29(9), 2018-2022. 
Wettschureck, N., \& Offermanns, S. (2005). Mammalian G-proteins and their cell type specific functions. Physiol Rev, 85(4), 1159-1204.

Whalen, E.J., \& Lewis, S.J. (1999). In vivo evidence that isoproterenol may increase heart rate in the rat by mechanisms in addition to activation of cardiac $\beta_{1}$-or $\beta_{2}$-adreneoreceptors. Eur J Pharmacol, 382(15), 207-210.

Wild, S., Roglic, G., Green, A., Sicree, R., \& King, H. (2004). Global prevalence of diabetes: estimates for the year 2000 and projections for 2030. Diab Care, 27(5), 1047-1053.

Wiley, L.A., Rupp, G.R., \& Steinle, J.J. (2005). Sympathetic innervation regulates basement membrane thickening and pericyte number in rat retina. Invest Ophthalmol Vis Sci, 47(2), 744-748.

Williams, K.P., \& Steinle, J.J. (2009). Maintenance of beta-adrenergic receptor signaling can reduce Fas signaling in human retinal endothelial cells. Exp Eye Res, 89(4), 448-455.

Williams, S.D., \& Ford, D.A. (2001). Calcium-independent phospholipase A(2) mediates CREB phosphorylation and c-fos expression during ischemia. Am J Physiol Heart Circ Physiol, 281(1), H168-H176.

Xiaochua, W., Reiter, R., Antonetti, D.A., Kimball, S.R., Jefferson, L.S., \& Gardner, T.W. (2004). Insulin promotes rat retinal neuronal cell survival in a p70s6k-independent manner. J Biol Chem, 279(10), 9167-9175.

Yamada, P.M., \& Lee, K.W. (2009). Perspectives in mammalian IGFBP-3 biology: local vs. systemic action. Am J Physiol, 296, C954-C976.

Ziyun, D.U., Wei, L., Murti, A., Pfeffer, S.R., Fan, M., \& Yang, C.H. et al. (2007). Non-conventional signal transduction by type I interferons: The NF-kB pathway. J Cell Biochem, 102(5), 1087-1094. 


\section{VITA}

Kimberly Williams-Guy (Kimberly Patrice Williams) was born to Eddie Lee Williams and Karen Patricia Williams in 1986. She was raised in her hometown of Memphis, Tennessee, where she graduated with honors from Central High School in May 2004. Kimberly then went on to attend the elite Christian Brothers University, and graduated with a degree in biology and chemistry in May 2008. While Kimberly attended Christian Brothers University, she was an active member in the department of biology, where she was a full-time member of the beta beta beta biology honor society and received many other scientific awards and recognitions.

After discovering a hidden passion and talent for research after an ophthalmology fellowship in June 2007, Kimberly enrolled in the University of Tennessee Health Science Center's Master of Science program in August 2008. While at the University of Tennessee Health Science Center, Kimberly worked on various aspects of her graduate project and collaborated with many professions in the field of ophthalmology. The primary investigator throughout the duration of Kimberly's graduate career was Dr. Jena J. Steinle, who came to The University of Tennessee Health Science Center in 2007. Kimberly's research finding were presented at scientific meetings such as The Association for Research in Vision and Ophthalmology (ARVO) in May 2008, 2009, 2010, and 2011 in Ft. Lauderdale, Florida. 